\title{
Synaptic Deficits at Neuromuscular Junctions in Two Mouse Models of Charcot-Marie-Tooth Type 2d
}

\author{
Emily L. Spaulding, ${ }^{1,2}$ - James N. Sleigh, ${ }^{3}$ Kathryn H. Morelli, ${ }^{1,2}$ Martin J. Pinter, ${ }^{4}$ Robert W. Burgess, ${ }^{1}$ \\ and ${ }^{\odot}$ Kevin L. Seburn ${ }^{1}$ \\ ${ }^{1}$ The Jackson Laboratory, Bar Harbor, Maine 04609, ${ }^{2}$ Graduate School of Biomedical Science and Engineering, University of Maine, Orono, Maine 04469, \\ ${ }^{3}$ Nuffield Department of Clinical Neurosciences, University of Oxford, Oxford OX3 9DU, United Kingdom, and ${ }^{4}$ Emory University, Atlanta, Georgia 30322
}

Patients with Charcot-Marie-Tooth Type 2D (CMT2D), caused by dominant mutations in Glycl tRNA synthetase (GARS), present with progressive weakness, consistently in the hands, but often in the feet also. Electromyography shows denervation, and patients often report that early symptoms include cramps brought on by cold or exertion. Based on reported clinical observations, and studies of mouse models of CMT2D, we sought to determine whether weakened synaptic transmission at the neuromuscular junction (NMJ) is an aspect of CMT2D. Quantal analysis of NMJs in two different mouse models of CMT2D ( Gars $^{P 278 K Y}$, Gars ${ }^{\text {C201R }}$ ), found synaptic deficits that correlated with disease severity and progressed with age. Results of voltage-clamp studies revealed presynaptic defects characterized by: (1) decreased frequency of spontaneous release without any change in quantal amplitude (miniature endplate current), (2) reduced amplitude of evoked release (endplate current) and quantal content, (3) age-dependent changes in the extent of depression in response to repetitive stimulation, and (4) release failures at some NMJs with high-frequency, long-duration stimulation. Drugs that modify synaptic efficacy were tested to see whether neuromuscular performance improved. The presynaptic action of 3,4 diaminopyridine was not beneficial, whereas postsynaptic-acting physostigmine did improve performance. Smaller mutant NMJs with correspondingly fewer vesicles and partial denervation that eliminates some release sites also contribute to the reduction of release at a proportion of mutant NMJs. Together, these voltage-clamp data suggest that a number of release processes, while essentially intact, likely operate suboptimally at most NMJs of CMT2D mice.

Key words: 3,4 diaminopyridine; axonal neuropathy; neuromuscular transmission; physostigmine; quantal content; voltage clamp

\section{Significance Statement}

We have uncovered a previously unrecognized aspect of axonal Charcot-Marie-Tooth disease in mouse models of CMT2D. Synaptic dysfunction contributes to impaired neuromuscular performance and disease progression. This suggests that drugs which improve synaptic efficacy at the NMJ could be considered in treating the pathophysiology of CMT2D patients.

\section{Introduction}

Charcot-Marie-Tooth (CMT) disease was described more than a century ago (Charcot and Marie, 1886; Tooth, 1886) and encom-

\footnotetext{
Received May 4, 2015; revised Feb. 3, 2016; accepted Feb. 9, 2016

Author contributions: R.W.B. and K.L.S. designed research; E.L.S., J.N.S., K.H.M., and K.L.S. performed research; M.J.P. contributed unpublished reagents/analytic tools; E.L.S., J.N.S., and K.L.S. analyzed data; K.L.S. wrote the paper.

This work was supported by R03-NS081334 (K.L.S.), R01-NS054154 (R.W.B.). We thank the Scientific Services at The Jackson laboratory, particularly Pete Finger, for muscle sample preparation and technical assistance with electron microscopy, and Mark Lessard for technical assistance with 3D imaging and quantification of bassoon-stained junctions. The Scientific Services at Jackson are supported in part by NCI Cancer Center Support (CA034196); Bangor Christian High School, honor biology students Dylan Merchant, Zach Palmeter, and Cody Collins for their assistance with analysis of electron micrographs; and summer student Lauren Budd for her contribution to bassoon immunohistochemistry and Sam Murray for assistance with collection of wire-hang data.

The authors declare no competing financial interests.

Correspondence should be addressed to Dr. Kevin L. Seburn, Research Scientist, The Jackson Laboratory, 600 Main Street, Bar Harbor, Maine 04609. E-mail: kevin.seburn@jax.org.
}

passes a large group of genetically and phenotypically heterogeneous diseases that affect the peripheral nerve at a worldwide frequency of at least $1 / 2500$ (Skre, 1974). In this study, we focus on CMT2D, which is a type 2 axonal CMT (Dyck, 1975) caused by autosomal dominant mutations in Glycyl tRNA synthetase (GARS; Antonellis et al., 2003).

CMT2D patients present with a range of "classic" CMT2 symptoms that include slowly progressive, distal weakness with or without sensory abnormalities. The absence of sensory involvement may result in a diagnosis of distal spinal muscular atrophy type V, which is allelic to CMT2D (Antonellis et al., 2003; Sivakumar et al., 2005; Rohkamm et al., 2007). Clinical reports on CMT2D and other type 2 CMT patients describe electrophysiological abnormalities including aberrant spontaneous muscle ac- 
tivity, reduced compound muscle action potentials, and less commonly, decreased nerve conduction velocities (Sivakumar et al., 2005; Shen et al., 2011; Saporta and Shy, 2013). Some CMT2D patients report early symptoms that included cramping in hands and legs either in response to cold or upon exertion, and transient episodes of weakness and fatigue that slowly worsen with age (Sivakumar et al., 2005). These electrophysiological signatures and other symptoms of type 2 CMTs are typically attributed to axonal degeneration (Sivakumar et al., 2005), but are also consistent with possible neuromuscular junction (NMJ) dysfunction and transmission failure. To our knowledge, this possibility has not been systematically investigated for type 2 axonal CMTs. If synaptic defects are indeed an unrecognized factor in type 2 CMTs, even as a secondary effect of axonal pathology, it would open a possible new treatment avenue for patients. For example, patients with NMJ defects due to congenital myasthenias, are effectively treated with drugs that modulate synaptic efficacy (Engel et al., 2015) and if myasthenia-like deficits were a component of type $2 \mathrm{CMT}$, drugs to improve NMJ transmission could be considered.

The dominantly inherited mutations in GARS (Antonellis et al., 2003) underlying CMT2D have been successfully modeled through mouse genetics, with the identification of dominant Gars alleles that recapitulate most aspects of CMT2D, including axon atrophy and loss, denervation, muscle weakness, and consistently more severe symptoms in certain distal muscles than proximal ones (Seburn et al., 2006; Achilli et al., 2009; Motley et al., 2011; Sleigh et al., 2014). The severity of CMT2D varies widely among patients due, in part, to the specific GARS mutation that an individual carries (Antonellis et al., 2003; Del Bo et al., 2006; Dubourg et al., 2006; James et al., 2006), and a similar correlation exists for different mutant alleles of Gars mice (Seburn et al., 2006; Achilli et al., 2009; Sleigh et al., 2014). Here we focus on two mutant mouse strains, one referred to as Gars $^{P 278 K Y}$, which develops a severe peripheral neuropathy (Seburn et al., 2006), and the second, Gars ${ }^{C 201 R}$, which has a milder disease (Achilli et al., 2009). Both mutant strains are weaker than age-matched wildtypes and weakness correlates with disease severity. Differences in muscle strength between the mild and severely affected CMTD2 mice may be partly due to early axon loss $(\sim 30 \%)$ in the Gars $^{P 278 K Y}$ mice that is not seen in the Gars ${ }^{C 201 R}$ allele. However, motor axon number in Gars ${ }^{P 278 K Y}$ largely stabilizes after $\sim 5$ weeks of age, whereas there is no reduction in axon number in Gars $^{\text {C201R }}$ nerves (Seburn et al., 2006; Achilli et al., 2009). Despite essentially stable axon counts, both alleles have a persistent, overt tremor that worsens gradually with age,(Seburn et al., 2006; Achilli et al., 2009; Motley et al., 2011; Sleigh et al., 2014) which could be caused by unreliable neuromuscular transmission at innervated terminals. Consistent with this idea is the previous finding that Gars ${ }^{P 278 K Y}$ muscle showed a more marked decrement in an integrated electromyogram (EMG) during tetanic contraction than wild-type (Seburn et al., 2006). In addition, both Gars mutant strains show muscle atrophy and some degree of morphological abnormality at the NMJ (Seburn et al., 2006; Motley et al., 2011; Sleigh et al., 2014) that may be indicative of ongoing synaptic dysfunction, but it is currently unknown whether intact NMJs function normally in CMT2D, or any other type 2 axonal CMT.

\section{Materials and Methods}

Mice. The mice used in these experiments were obtained from research colonies maintained at The Jackson Laboratory. The two strains of Gars mutant mice are established models of CMT2D and are described in several previous publications (Seburn et al., 2006; Achilli et al., 2009; Motley et al., 2011; Stum et al., 2011). Briefly, one strain of mice (CAST; B6-Gars ${ }^{\text {Nmf249 } / J R w b ; ~ S t o c k ~ n o . ~ 17540 ; ~ S e b u r n ~ e t ~ a l ., ~ 2006) ~ c a r r y ~ a ~ s p o n-~}$ taneous dominant mutation (insertion) that results in a $\mathrm{P}$ to $\mathrm{KY}$ substitution at amino acid 278 of the GlyRS protein. These mice hereafter referred to as Gars ${ }^{P 278 K Y}$; develop overt disease symptoms by $2-3$ weeks of age. A second strain of mice (C3H/HeH-Gars ${ }^{\text {C201R }}$; Achilli et al., 2009) carry an $\mathrm{N}$-ethyl- $\mathrm{N}$-nitrosourea (ENU)-induced dominant point mutation that causes a cysteine to arginine substitution at residue 201 of the GlyRS protein. These mice (hereafter Gars ${ }^{C 201 R}$ ) have a qualitatively similar, but generally milder CMT2D phenotype. Both Gars ${ }^{P 278 K Y}$ and Gars $^{C 201 R}$ mutant strains are routinely maintained by mating heterozygous male mutant mice to female wild-type mice. For these experiments, additional matings were set up using female mice homozygous for a transgene expressing yellow fluorescent protein (B6.Cg- Tg(Thy1YFP)16Jrs/J; Stock no. 3709, hereafter YFP16; Feng et al., 2000). Litters from these matings produced the necessary controls (YFP16; Gars $^{+/+}$), as well as either YFP16; Gars ${ }^{P 278 K Y}$ or YFP16; Gars ${ }^{C 201 R}$. Colonies of Gars mice also carrying the YFP transgene have been maintained for several years and neither the onset nor lifespan of either strain has changed. In addition, results of analyses performed on these mice are in good agreement with our previous results on mutants that did not carry the YFP transgene. All mice were maintained in the same vivarium on a $12 \mathrm{~h}$ light/dark cycle and were provided food and water ad libitum. Care and procedures were reviewed for compliance and approved by the Animal Care and Use Committee of The Jackson Laboratory.

NMJ immunohistochemistry and analysis of innervation status. CMT2D mice had been crossed to mice carrying the transgene for yellow fluorescent protein that allowed visualization of the presynaptic nerve (for details, see Mice). Thus, for analysis, the levator auris longus (LAL) muscle was removed and placed in $2 \%$ paraformaldehyde for $15 \mathrm{~min}$ and then rinsed three times in PBS. Finally, to visualize postsynaptic acetylcholine receptors (AChRs) on the muscle cell surface, muscles were incubated with $\alpha$-bungarotoxin conjugated with AlexaFluor 594 (NMJ only) or 647 (NMJ costaining with Bassoon, see below; (1/2000; Invitrogen) in cold PBS containing 2\% BSA, 2\% normal goat serum, and $0.1 \%$ Triton for 20 min. Muscles were then examined by fluorescent microscopy (Nikon E6000) at a magnification of $63 \times$. In each muscle 100 NMJs were randomly viewed and classified as described previously (Seburn et al., 2006). Junctions where the nerve completely overlapped the AChRs on the muscle were defined as fully occupied, those with a portion of receptors clearly vacated by the presynaptic nerve were defined as partially occupied, and those with AChR plaques that had no associated nerve were defined as denervated.

Bassoon staining and quantification of release sites. Muscles were prepared, and presynaptic and postsynaptic components of the NMJ were visualized, as described above. Immunohistochemistry followed a published protocol (Nishimune, 2012). In addition, muscles were incubated overnight with a mouse primary antibody against the active zone protein Bassoon (1/1000; SAP7F407, Enzo Life Sciences) and fluorescently conjugated secondary (Zenon AlexaFluor 568 Mouse IgG2a, Life Technologies, catalog \#Z2506). Images were collected as Z-series using a Leica SP5 confocal microscope. Bassoon-stained active zones were quantified using $3 \mathrm{D}$ reconstructions (Imaris v7.4.2, Bitplane) of NMJs. Using this software, each $\mathrm{NMJ}$ was reconstructed and then evaluated empirically by rotating and examining the $3 \mathrm{D}$ image from presynaptic and postsynaptic perspectives to determine that the reconstruction matched the actual staining. Briefly, for each image, the postsynaptic receptor area was rendered by smoothing and thresholding using background subtraction based on local contrast. The result was then filtered based on a minimal voxel size to eliminate any artifactual staining not associated with the terminal area. The volume and surface area of the rendered volume were determined by the software. Puncta stained with bassoon were identified and counted in a three-step process. First, it was determined on wild-type NMJs that a background subtraction that eliminated "spots" with a diameter $>0.250 \mu \mathrm{m}$ removed the majority of extra-junctional "puncta." For each image, this result was then filtered to include only spots above a fixed intensity at the center of the spot. Finally, the spots needed to associate with the presynaptic side, within the perimeter defined by post- 
synaptic staining. The intensities used for filtering were determined empirically for each image by thresholding the appropriate channel and noting the value giving the best representation of visible staining. Using this approach gave wild-type results similar to those reported previously (Nishimune, 2012).

Muscle preparation and voltage-clamp. Mice were anesthetized with isoflurane $(2 \%, 300 \mathrm{ml} / \mathrm{min})$ to remove the intact LAL muscle. This flat muscle controls the movement of the ear and is a well characterized mixed fiber-type muscle (Angaut-Petit et al., 1987). Muscles were placed immediately in a specially designed recording chamber and pinned onto the silastic such that solution could flow freely across the tissue on both sides. The recording chamber was perfused continuously with Ringer's solution comprised of (in mmol/L): $118 \mathrm{NaCl}, 3.5 \mathrm{KCl}, 2 \mathrm{CaCl}_{2}, 0.7$ $\mathrm{MgSO}_{4} 26.2, \mathrm{NaHCO}_{3}, 1.7 \mathrm{NaH}_{2} \mathrm{PO}_{4}$, and 5.5 glucose, and equilibrated with $95 \% \mathrm{O}_{2} / 5 \% \mathrm{CO}_{2}$ to maintain a $\mathrm{pH}$ of 7.3-7.4. The solution was at room temperature $\left(20^{\circ}-22^{\circ} \mathrm{C}\right)$ for all experiments. Voltage-clamp experiments followed previously described methods (Rich et al., 2002; Wang et al., 2004, 2005). Once the muscle was pinned the tissue was stained by the addition of 4-(4-diethylaminostyryl)- $N$-methylpyridinium iodide (4-Di-2ASP; Magrassi et al., 1987) at a concentration of $\sim 2 \mu \mathrm{M}$ for $2.5 \mathrm{~min}$. This method provides staining sufficient for visualization of the superficial nerve terminals and the surface of the muscle fibers. A concentric bipolar electrode (FHC) was placed in contact with the nerve and connected to the stimulator (WPI A360). Stimulator output was capacitively coupled to the electrode to avoid potential damage from DC polarizing currents (Guyton and Hambrecht, 1974). The preparation was then placed under an upright epifluorescence microscope (Leica DMLFSA). Electrodes (5-10 M $\Omega$ ) were filled with $3 \mathrm{M} \mathrm{KCL}$ and 10 $\mathrm{ng} / \mathrm{ml}$ of sulforhodamine so that the electrode tip could be seen under the microscope. Synapses were located and fibers were impaled within 100 $\mu \mathrm{m}$ of the terminal and voltage-clamped to $-50 \mathrm{mV}$. In initial experiments muscle fibers were crushed away from the endplate band to avoid movement induced by nerve stimulation (Glavinović, 1979; Wang et al., 2004, 2005), but in most experiments the muscle-specific sodiumchannel blocker ( $\mu$-Conotoxin GIIIB, Alomone Labs; Cruz et al., 1985; Robitaille and Charlton, 1992) was introduced $(\sim 1 \mu \mathrm{M})$ to eliminate muscle action potentials and contraction.

Wire-hang test. A variation on the wire-hang test (Gomez et al., 1997; Rafael et al., 2000) was used to assess the response to drugs that enhance synaptic function via either presynaptic or postsynaptic mechanisms. Briefly, mice were placed on a 6 " $\times 9$ " piece of wire mesh and then the mesh was inverted and held $\sim 6$ " above the countertop. The latency (seconds) to a fall was timed and recorded, up to a maximum of $1 \mathrm{~min}$. Tests were performed at approximately the same time each day. Each mouse performed three trials in a given session and a rest period of at least $30 \mathrm{~s}$ was given between individual trials. To allow the mice time to adjust to the wire-hang test and learn how to perform, animals were given at least three consecutive daily practice sessions before drug administration and testing trials.

In drug/vehicle trials, drugs were prepared fresh from frozen stock on each day (in sterile PBS, $0.1 \mathrm{mg} / \mathrm{kg}$ - physostigmine; $2.5 \mathrm{mg} / \mathrm{kg}, 3,4 \mathrm{di}$ aminopyridine (3,4-DAP; Sigma-Aldrich). Each mouse performed a preinjection trial, and then was injected intraperitoneally and retested 60 min later. Mice were dosed three independent times in $5 \mathrm{~d}$ with intervening practice days. The best wire-hang score in three trials is reported for that day ( 3 trials/d on 3 test days). Performance was calculated as preinjection/postinjection latency-to-fall, expressed as a percentage. The average percentage difference is calculated from the 3 independent days of injections.

Data collection and analysis. Custom software was used for collection and analysis of synaptic currents. At each NMJ, spontaneous miniature endplate currents (MEPCs) were collected for $1 \mathrm{~min}$. The nerve was then stimulated $(0.5 \mathrm{~Hz})$ and $15-20$ individual evoked endplate currents (EPCs) were recorded. Quantal content was directly calculated by dividing the EPC amplitude by the average MEPC amplitude recorded for each synapse. We used the extent of EPC facilitation/depression during evoked trains (Zucker and Regehr, 2002) to indirectly evaluate probability of release following a protocol previously used at the mouse NMJ (Kong et al., 2009; Wang et al., 2010). We recorded 15-20 responses to a
10 pulse, $50 \mathrm{~Hz}$ train delivered to the nerve and 20 responses were recorded. The extent of depression/potentiation was calculated by dividing the averaged amplitude of the 10th pulse by the first pulse.

Electron microscopy. For electron microscopy, muscles were processed as previously described (Burgess et al., 2010). In brief, muscles were fixed in $2 \%$ paraformaldehyde, $2 \%$ glutaraldehyde in $0.1 \mathrm{~m}$ cacodylate buffer. The endplate-containing region was isolated and embedded, and then sectioned for transmission electron microscopy. Seventy-five nanometer plastic sections were mounted on grids and viewed using a Jeol 1230 electron microscope equipped with a Hamamatsu digital camera system for image collection.

Statistics. Unless otherwise noted averaged numbers are reported as mean \pm SE. We used a nested ANOVA (using animal as a random factor) for genotype by age comparisons of electrophysiology, active zones, and vesicle data. This statistic controls for animal-to-animal variation and the effect of taking small samples to represent a larger population. We also evaluated interactions for 2 and 4 month electrophysiology data using a standard two-way ANOVA (genotype by age), but the results did not modify any conclusions so results derived from the more appropriate nested design are reported. A Student's $t$ test was used for comparison of wire-hang and quantal content comparison of $70 \mathrm{~Hz}$ voltage-clamp data. In all cases, the statistical cutoff for declaring a significant difference was $p<0.05$.

\section{Results}

Proximal LAL muscles in CMT2D mice show prevalent NMJ dysmorphology, but most terminals retain innervation

The proximal LAL muscle has not previously been examined in CMT2D mice, so before conducting voltage-clamp experiments we evaluated NMJ morphology and assessed innervation status. Compared with wild-type terminals (Fig. $1 A, B$ ) nearly all LAL terminals, in both Gars ${ }^{\text {P278KY }}$ (Fig. 1C-I) and Gars ${ }^{\text {C201R }}$ (Fig. $1 J-L)$ muscles, have evident dysmorphology that includes more diffuse postsynaptic staining with less distinct guttering as well as thinner axons and presynaptic nerves. As with other previously studied muscles NMJ dysmorphology varies with disease severity (severe Gars $^{P 278 K Y}>$ mildGars ${ }^{C 201 R}$ ) and can range from subtle, near normal looking NMJs to clearly fragmented junctions (Fig. 1compare $J, K$ ). At low-magnification an innervating presynaptic axon is evident at most NMJs in LAL muscles of even the more severely affected Gars ${ }^{P 278 K Y}$ mice (Fig. $1 C-E$ ), but at highermagnification some of these junctions are found to be only partially innervated even in the mildly affected Gars ${ }^{C 201 R}$ mice (Fig. $1 G-I, L)$. Indeed, the most striking difference in LAL NMJs between CMT2D alleles was the extent of partial denervation (Fig. $1 F)$. In Gars $^{P 278 K Y}$ muscles from 2-month-old mice, more than one-half of the junctions were partially innervated, whereas in muscles of 4-month-old Gars ${ }^{C 201 R}$ mice only $\sim 5 \%$ of NMJs had this status. There were also more than three times as many denervated junctions in the Gars ${ }^{P 278 K Y}$ than in the Gars ${ }^{C 201 R}$ muscles (6.5 vs 1.9\%) even though the latter were 2 months older. Synaptic function is likely to be compromised at junctions that are not fully occupied by a presynaptic terminal if other processes cannot compensate. Our analysis of the LAL predicts that innervation status could contribute to observed changes in synaptic function at Gars ${ }^{P 278 K Y}$ NMJs of 2-month-old mice where $~ 50 \%$ of NMJs are incompletely innervated. In contrast, because $\sim 95 \%$ of NMJs in the Gars ${ }^{C 201 R}$ LAL are fully innervated, even at 4 months, functional changes would be independent of innervation status at most NMJs.

\section{Quantal analysis reveals abnormal synaptic transmission in CMT2D mice at 2 months of age}

Motor endplate current recordings were made under voltageclamp conditions to control for potential changes in passive properties of muscle fibers that could occur with disease-related 

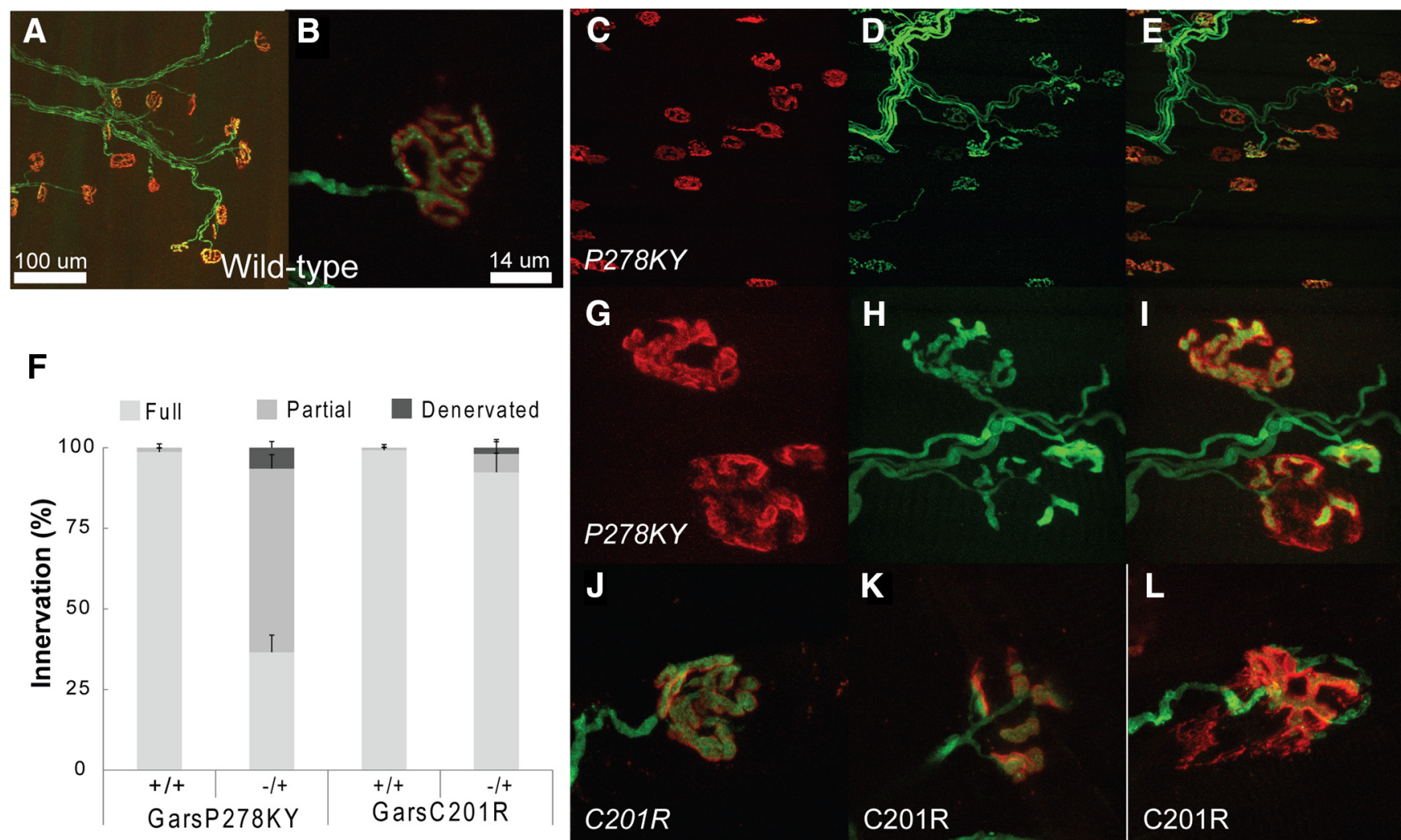

K

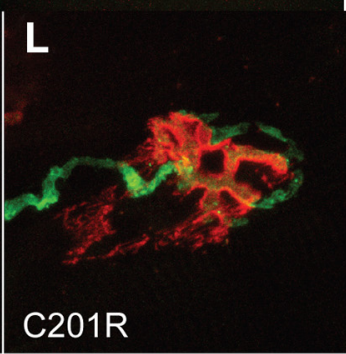

Figure 1. Morphological analysis of LAL muscle in CMT2D mice. Images shown are of LAL terminals in 2 month-old $(\boldsymbol{A}, \boldsymbol{B})$ wild-type, $(\boldsymbol{C}-\boldsymbol{I})$ Gars ${ }^{\text {P278KY }}$ and $(\boldsymbol{J}-\boldsymbol{L}) 4-$ month-old Gars ${ }^{\mathrm{C} 201 \mathrm{R}}$ mice. Red shows $\alpha$-bungarotoxin-stained postsynaptic ACh receptors, green is presynaptic nerve expressing YFP (see Materials and Methods). Innervation analysis $(\boldsymbol{F})$ included examination of $\geq 100$ terminals from each of three LAL muscles/genotype. Control wild-type $(\boldsymbol{A}, \boldsymbol{B})$ terminals show typical complex pretzel-like morphology and postsynaptic receptors are entirely apposed by the presynaptic nerve. At low-magnification $(20 \times)$ it can be seen that $(\boldsymbol{C}-\boldsymbol{E})$ Gars $^{P 278 K Y}$ terminals retain some innervation, but when viewed at highermagnification $(63 \times ; \boldsymbol{G}-\boldsymbol{I})$ nearly all terminals show some dysmorphology $(\mathbf{G}-\mathbf{I}$, upper and lower terminal) and many are only partially innervated (G-I, lower terminal). 0 ccupancy was analyzed, and $\sim 10 \%$ of terminals were denervated but $>50 \%$ showed some degree of partial denervation muscles. The LAL muscle in Gars ${ }^{\mathrm{C} 201 R}$ mice showed a similar phenotype to Gars $^{P 278 K Y}$ muscles, with widespread dysmorphology at most terminals with severity ranging from $(\boldsymbol{J})$ mild, near-normal to $(\boldsymbol{K})$ fragmented, or $(\boldsymbol{L})$ partially denervated. Overall, consistent with previous findings, Gars ${ }^{C 201 R}$ LAL muscles had many $(\boldsymbol{F})$ fewer denervated or partially denervated terminals than seen in Gars ${ }^{P 278 K Y}$, but across both alleles at least $80-90 \%$ of NMJs retain at least partial innervation.

changes in muscle activity (Lomo and Rosenthal, 1972). Our first set of experiments used muscles from 2-month-old Gars ${ }^{P 278 K Y}$ and Gars ${ }^{C 201 R}$ mutants and respective wild-type littermate controls. At this age, we found qualitatively similar changes in synaptic function for both mutants, but as with other documented phenotypes, the dysfunction was more pronounced at NMJs of the Gars ${ }^{P 278 K Y}$ mice than at synapses of Gars ${ }^{C 201 R}$ mutants with the milder disease.

At 2 months of age, both alleles show no difference in MEPC amplitude (quantal amplitude; Fig. $2 A, G$ ), but the frequency of spontaneous release was consistently and significantly lower than wild-type (Fig. $2 \mathrm{~B}, \mathrm{H}$ ). The finding that quantal amplitude at mutant synapses is not different from wild-type indicates that both postsynaptic receptor density and the amount of acetylcholine loaded into individual vesicles is unaffected at CMT2D terminals.

Evoked release was also affected at 2-month-old mutant NMJs, as both alleles showed significant decreases of $~ 25 \%$ in EPC amplitude (Fig. 2C,I) and quantal content (Fig. 2D,J). Clinical diagnoses of NMJ dysfunction uses response to repetitive stimulation (Rich, 2006), so we also examined changes in EPC amplitude in response to a 10 pulse, $50 \mathrm{~Hz}$ stimulus train. In addition, changes in facilitation or depression with this protocol can be used to infer changes in release probability (Zucker and Regehr, 2002; Kong et al., 2009). Using the ratio of the amplitude of the 10th/1st EPC in the train we found that, on average, NMJs of Gars ${ }^{P 278 K Y}$ and Gars ${ }^{C 201 R}$ mice showed significantly greater depression (Fig. 2E,K). For healthy synapses greater depression correlates with higher initial probability of release (Zucker and Regehr, 2002).

Finally, we examined time course measures of both MEPCs and EPCs and found no significant changes between mutant and control NMJs at 2 months of age for either allele. (Time constants in ms: MEPC control vs mutant- Gars $^{P 278 K Y}: 0.79 \pm$ 0.24 vs $0.74 \pm .0 .20$ Gars $^{C 201 R}: 0.75 \pm 0.12$ vs $0.73 \pm 0.12$; EPC control vs mutant: Gars $^{P 278 K Y}: 1.1 \pm 0.20$ vs $1.2 \pm .0 .24$, Gars $^{C 201 R}: 1.2 \pm 0.14$ vs $\left.1.2 \pm 0.17\right)$. Additional time course measures (time-to-peak, half-width, 10-90 rise time) also showed no changes at synapses in either Gars mutant at 2 months of age.

Together, analysis of synaptic measures reveals changes in synaptic transmission in 2-month-old CMT2D mice that are characterized by decreased spontaneous release frequency and evoked release amplitude and greater EPC depression in response to $50 \mathrm{~Hz}$ stimulation. The absence of any change in MEPC amplitude or time course measures points to a presynaptic defect. As with other CMT2D phenotypes examined previously, synaptic changes in the CMT2D mice correlate with disease severity associated with different mutant alleles. 

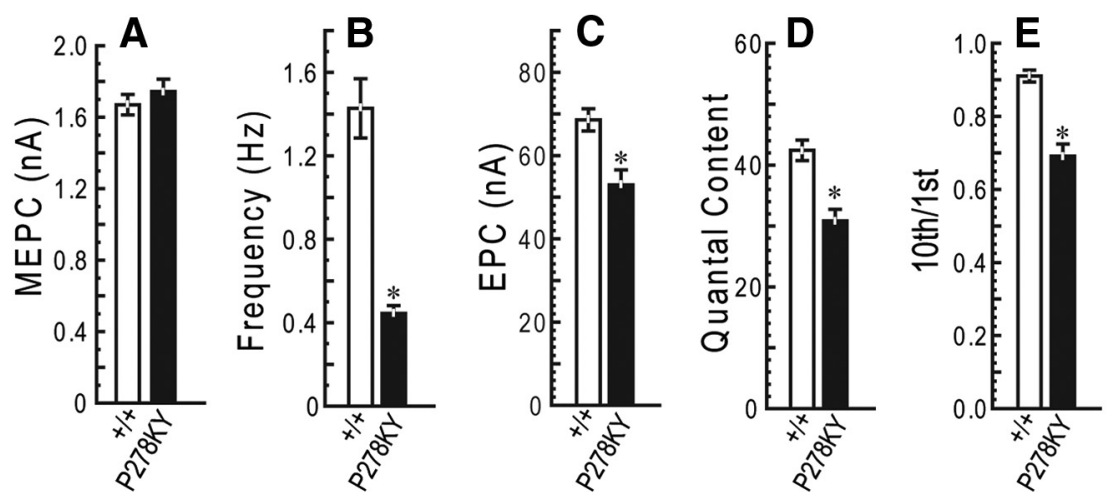

$\mathbf{F}$
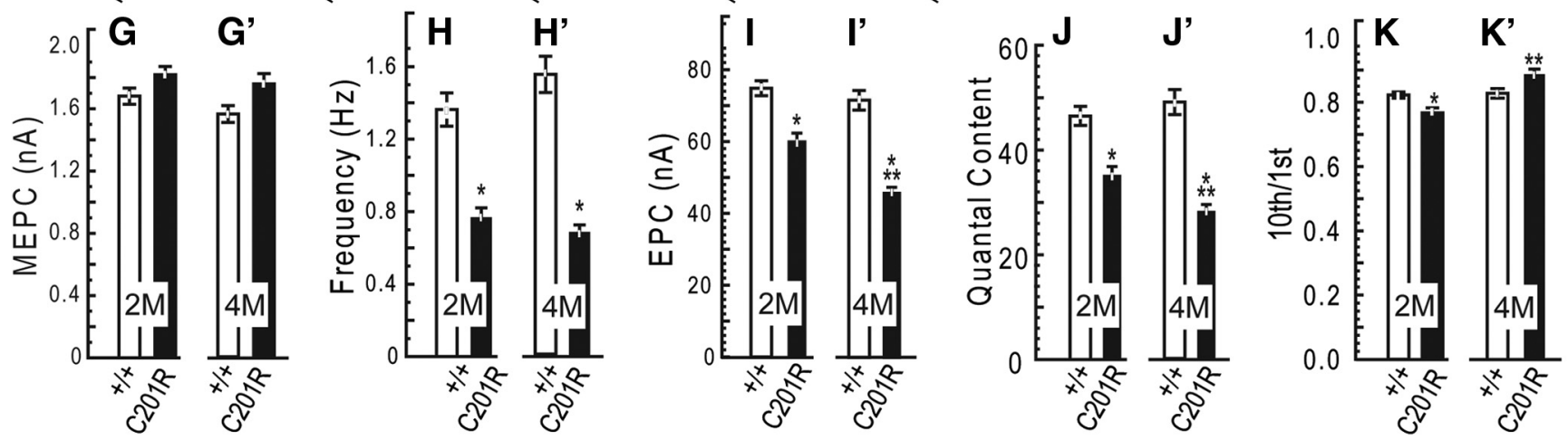

Figure 2. Quantal analysis. Voltage-clamp experiments were performed using LAL muscles from 2-month-old Gars ${ }^{\text {P278KY }}$, (top) and both 2- and 4-month-old Gars ${ }^{\text {(201R }}$ mice (bottom). All recordings were made at a holding potential of $-50 \mathrm{mV}$. At 2 months of age, mutant NMJs in both Gars ${ }^{P 278 K Y}$ and Gars ${ }^{C 201 R}$ mice showed: no change in MEPC amplitude, $(\boldsymbol{A}, \boldsymbol{G})$ lower-frequency of spontaneous release, $(\boldsymbol{B}, \boldsymbol{H})$ reduced EPC amplitude, and quantal content $(\boldsymbol{C}, \boldsymbol{I}, \boldsymbol{D}, \boldsymbol{J})$, and significantly greater depression $(10 \mathrm{th} / 1 \mathrm{st})$ in response to $50 \mathrm{~Hz}$ stimulation $(\boldsymbol{E}, \boldsymbol{K})$. At 4 months of age Gars ${ }^{\mathrm{C} 201 R}$ NMJs show no additional changes in spontaneous release $\left(\boldsymbol{G}^{\prime}, \boldsymbol{H}^{\prime}\right)$ but a further reduction in EPC amplitude and quantal content $\left(\boldsymbol{I}^{\prime}, \boldsymbol{J}^{\prime}\right)$ while repetitive stimulation produced less depression compared with 2 month mutant NMJs $\left(\boldsymbol{K}^{\prime}\right)$. $\boldsymbol{F}$, Increased extracellular calcium successfully increased spontaneous release frequency at 4-month-old mutant Gars ${ }^{\mathrm{C} 201 R}$ NMJ. LAL muscles of six different mice for each genotype/age were used. In each muscle recordings were made on 3-12 synapses (mean and mode $=8$ ) for a total of between 47 and 58 synapses for each genotype/age. Comparisons made using nested ANOVA. ${ }^{*} p<0.05$, mutant versus wild-type; ${ }^{* *} p<0.05$, 2 versus 4 months Gars ${ }^{\text {(201R }}$.

Quantal content is further reduced in Gars ${ }^{C 201 R}$ LAL terminals between 2 and 4 months

Given the relationship between synaptic dysfunction and disease severity across mutant alleles, we were also interested in determining whether synaptic measures changed with age for a given allele. For these experiments, we aged an additional cohort of Gars ${ }^{C 201 R}$ mice to 4 months. We chose the milder Gars ${ }^{C 201 R}$ allele for this study because innervation status is near normal even at the older age (Fig. $1 F)$.

The additional 2 months produced no significant changes in spontaneous release compared with younger mutants. MEPC amplitude recorded at Gars ${ }^{C 201 R}$ NMJs was still not different from control (Fig. 2G, $G^{\prime}$ ), and MEPC frequency remained reduced to approximately the same extent as measured at 2 months (Fig. $2 H, H^{\prime}$ ). Because the reduction in frequency of spontaneous release was such a robust, consistent finding, we were interested in determining whether a mutant synapse could increase spontaneous release in response to higher extracellular calcium. Raw traces show increased MEPC frequency when recorded from the same LAL synapse (4-month-old, Gars ${ }^{C 201 R}$ ) at two different calcium concentrations: typical $2 \mathrm{~mm}$ (Fig. 2F, top), and $4 \mathrm{~mm}$ (Fig. 2F, bottom). Initial release frequency was $0.4 \mathrm{~Hz}$, at the lower end of the range observed previously $\left(\sim 0.8 \mathrm{~Hz}\right.$; Fig. $\left.2 \mathrm{H}, H^{\prime}\right)$, but doubling extracellular calcium increased release frequency to 1.0 $\mathrm{Hz}$, within normal range for a wild-type synapse, a comparable relative increase to that reported previously for wild-type mice (Plomp et al., 2000). Average MEPC amplitude also increased from 1.9 to $2.3 \mathrm{~mA}$.
Evoked release at Gars ${ }^{C 201 R}$ synapses showed a further decline, as mean EPC amplitude and quantal content were significantly lower at 4 months compared with 2 month and age-matched wild-type values (Fig. $2 I, I^{\prime}, J, J^{\prime}$ ). Interestingly, the extent of depression in response to $50 \mathrm{~Hz}$ trains at the older mutant NMJs was significantly less (i.e., $>10$ th/1st ratio) compared with 2 month mutant values, and $>4$ month wild-type control values (Fig. $\left.2 K, K^{\prime}\right)$, indicating a decrease in the probability of release between 2 and 4 months.

Examination of time course measures (MEPC and EPC, data not shown) revealed neither an age-related effect of the Gars ${ }^{C 201 R}$ mutation nor any difference from age-matched controls.

\section{Dynamic frequency-related changes in evoked release show} atypical response at mutant $N M J$

Observations during the delivery of $50 \mathrm{~Hz}$ stimulus trains prompted a more detailed analysis of dynamics during the 10 pulse train. EPC amplitude was measured for each pulse of the train and expressed relative to the amplitude of the first EPC. The typical pattern of the $50 \mathrm{~Hz}$ frequency response averaged across wild-type littermate NMJs was similar regardless of age or strain (Fig. 3) and is characterized by potentiation of initial EPCs (2nd-4th response, $\sim 105 \%$ initial) followed by moderate depression (85-90\% initial). However, this pattern differed between mutant alleles and changed between 2 and 4 months in Gars $^{\text {C201R }}$ muscles.

At NMJs of 2-month-old CMT2D mice, both Gars ${ }^{P 278 K Y}$ (Fig. $3 A$ ) and Gars $^{C 201 R}$ (Fig. 3B) showed near complete absence of potentiation, barely evident only for the second response at NMJs 

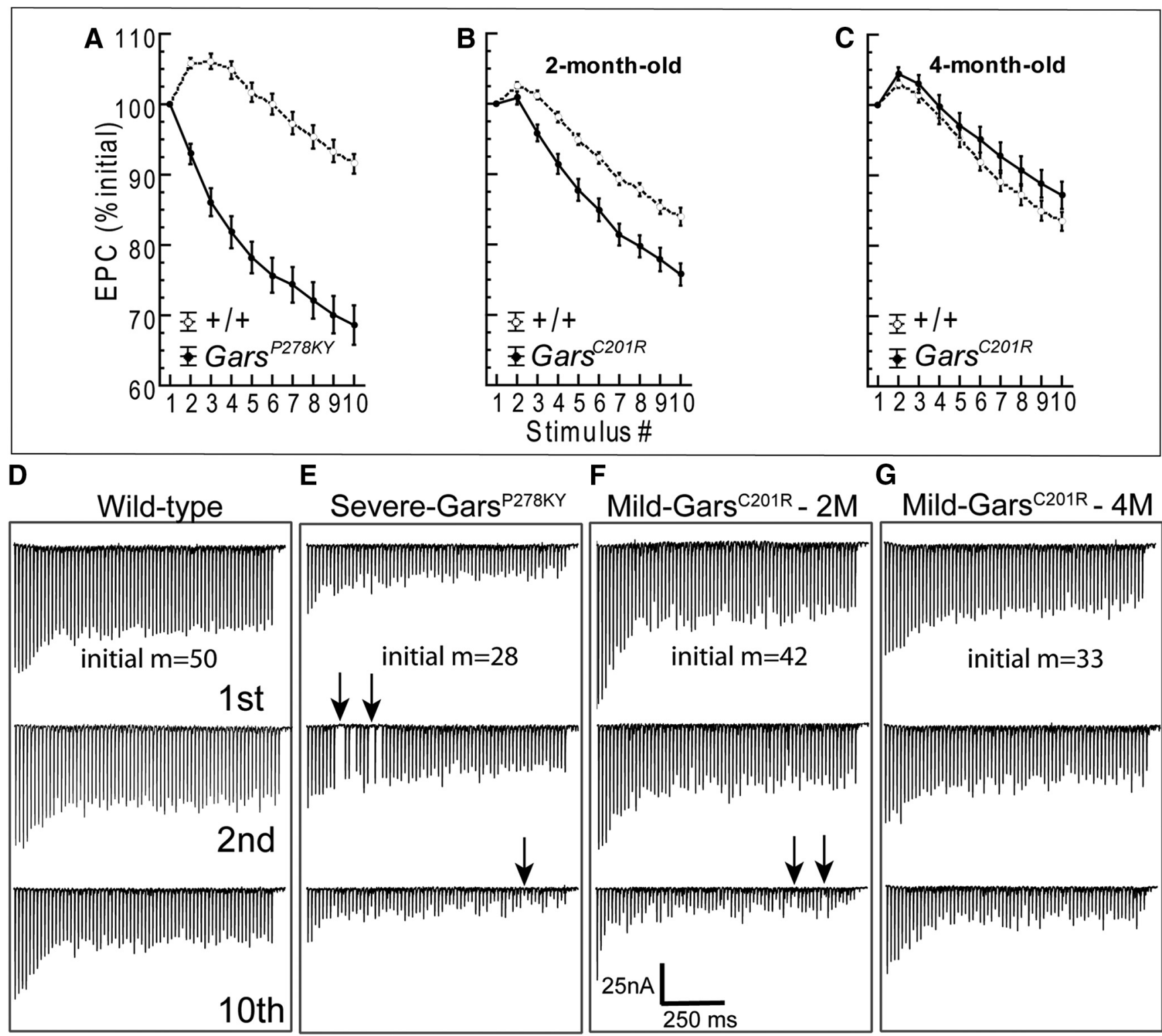
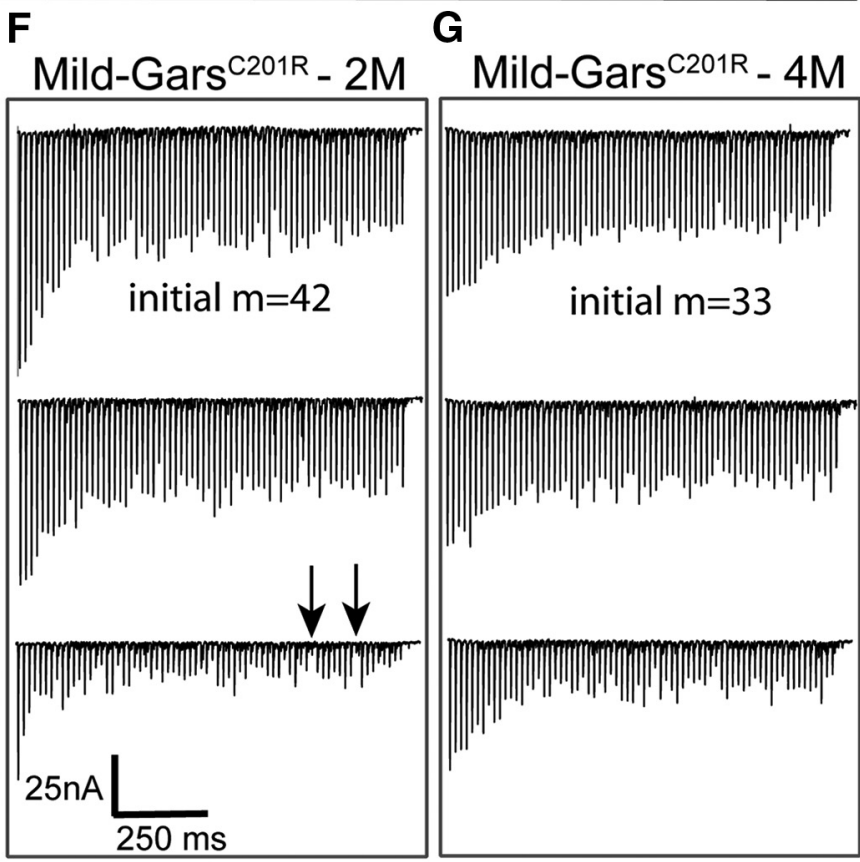

Figure 3. Evoked response to repetitive stimulation. $\boldsymbol{A}-\boldsymbol{C}$, show plots of averaged normalized EPC amplitude ( $\pm \mathrm{SE}$ ) for each stimulus of a 10 pulse, $50 \mathrm{~Hz}$ stimulus train (average of 20 trains at $0.5 \mathrm{~Hz}$ for each NMJ). In contrast to wild-type synapses, mutant NMJs in 2-month-old animals showed reduced or absent potentiation of initial EPCs and somewhat steeper depression. At 4 months of age, initial EPCs showed potentiation similar to wild-type. EPC amplitude was measured for each stimulus and plotted relative to the amplitude of the first pulse. Numbers of animals/synapses are the same as for data shown in Figure 2. Plots in $\mathbf{D}-\mathbf{G}$ show the first, second, and 10th raw traces from a series of 10 EPC trains recorded in response to a 70 pulse, $70 \mathrm{~Hz}$ stimulus ( $1 \mathrm{~s}$ duration), delivered every $2 \mathrm{~s}$. Starting quantal content $(\mathrm{m})$ is shown for each of the four NMJs. Mutant NMJs showed marked steadily progressive decrements from the first to 10th train, whereas the wild-type decreased and stabilized. The mutant NMJs are easily identified by comparing response to the 10th stimulus train (lower traces) to wild-type. In addition, clear failures of release were evident (arrows) for NMJs from severe and 2-month-old mild Gars ${ }^{\text {C201R }}$ muscles. Failures were present in at least one train for 5 of 11 mutant NMJs, but were never observed in wild-type. The $1 \mathrm{~s}$ duration, $70 \mathrm{~Hz}$ trains were recorded in nine different muscles/experiments $(n=5,6,3$, and $2 \mathrm{NMJs}$ from 4-month-old wild-type, $4 \mathrm{M}$-Gars ${ }^{(201 R}, 2 \mathrm{M}$-Gars ${ }^{\mathrm{C} 201 R}$, and 2M-Gars ${ }^{\text {P278KY }}$, respectively).

of Gars ${ }^{\text {C201R }}$ mice. In addition, EPCs at NMJs for both mutant alleles showed a slightly steeper depression relative to respective wild-type (Fig. $3 A, B$ ), and the effect is again more marked at

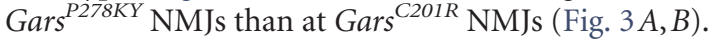

Given the additional reduction in quantal content at Gars ${ }^{\mathrm{C} 201 \mathrm{R}}$ NMJs between 2 and 4 months, we expected the response pattern of 4 month mutant NMJs to appear more like that observed at Gars $^{P 278 K Y}$ terminals. To our surprise, the typical early potentiation was now evident and the overall pattern was more similar to wild-type, but with even slightly greater initial potentiation and somewhat less marked depression (decreased probability of release) in later responses (Fig. 3C).
In Gars mutants observable weakness occurs during behaviors lasting seconds rather than milliseconds. Thus, we were also interested in the ability of mutant NMJs to sustain release for periods longer than the $200 \mathrm{~ms}$ duration of the 10 pulse $50 \mathrm{~Hz}$ trains. To accomplish this at NMJs where a sufficiently stable penetration was established, we also recorded EPCs in response to 10 consecutive stimulus trains of $1 \mathrm{~s}$ duration $(70$ pulses at $70 \mathrm{~Hz})$ delivered once every $2 \mathrm{~s}$. Successful recordings, of at least 10 stimulus trains per NMJ, were made in several muscles at 16 different NMJs including five wild-type and 11 mutants (2 Gars $^{P 278 K Y}$ and 9 Gars ${ }^{C 201 R}, 3$ and 6 from 2- and 4-month-old muscles, respectively). Overall, qualitative examinations of $70 \mathrm{~Hz}$ 
raw traces reveal that mutant NMJs do not sustain release during the repeated $1 \mathrm{~s}$ stimulus as well as wild-type (Fig. 3D-G). If the response to the first train in a series is compared across genotype/ age ( $D-G$, top), a marked difference is only clearly evident for the severe Gars ${ }^{P 278 K Y}$ NMJ, but effects on each mutant NMJ becomes more marked with successive trains such that by the 10th train ( $D-G$, bottom) release is clearly more severely reduced at mutant NMJs. In traces shown, release failures occur in the second train at the Gars ${ }^{P 278 K Y}$ NMJ (Fig. $3 E$, middle, arrows) and during the 10th train for both Gars ${ }^{P 278 K Y}$ and 2-month-old Gars ${ }^{C 201 R}$ NMJs shown (Fig. $3 E, F$, bottom, arrows). We examined all individual $70 \mathrm{~Hz}$ traces for each NMJ to better evaluate the extent of the failures. Failures never occurred at wild-type NMJs, but at least one failure occurred during at least one stimulus train at 5 of 11 mutant NMJs. Of these five, two were from Gars ${ }^{P 278 K Y}$ muscles and three were recorded in 2-month-old old Gars ${ }^{C 201 R}$ muscles. Failures for both Gars $^{P 278 K Y} \mathrm{NMJs}$ occurred as early as the second stimulus train and failures also occurred during the initial 10 stimuli of the train, whereas for Gars ${ }^{C 201 R}$ NMJs (2 month), failures did not appear until the fourth train or later and failures were not seen within the initial 10 stimuli of any train. The $50 \mathrm{~Hz}$ analysis above suggested a compensatory response between 2 and 4 months for Gars ${ }^{C 201 R}$ NMJs, and in keeping with this, examination of traces for 4-month-old Gars ${ }^{\text {C201R }}$ NMJs revealed no clear failures, but traces included intermittent, very small EPCs (5-15 nA), not present in any wild-type traces, and these were more common toward the end of individual traces and in later (4-10th) trains.

We also calculated quantal content using the EPC averaged across trains $(n=10 / \mathrm{NMJ})$ of the 70 th EPC in the trains and compared mutant and wild-type values. Final quantal content at the end of the $70 \mathrm{~Hz}$ trains ranged between 21 and 49 for the five wild-type NMJs and between 5 and 22 for the 11 mutant synapses. Including all mutant data, the average mutant quantal content of the final $70 \mathrm{~Hz}$ EPC (mean $13.2 \pm 5$ ) was significantly lower than wild-type (mean $\left.31.4 \pm 12 ; t_{(14)}=4.4, p=0.01\right)$ and this difference was also significant if the comparison was restricted to 4-month-old Gars ${ }^{C 201 R}$ (mean $13.5 \pm 3$ ) and wild-type $\left(t_{(9)}=3.5, p=0.01\right)$.

Together the data on the response of Gars mutant NMJs to repetitive stimulation suggest impaired vesicle recycling compared with wild-type. The cumulative intra- and inter-train decrements shown in Figure 3 are consistent with such a deficiency and suggests multiple processes likely contribute to defective synaptic transmission.

As a final assessment of the severity of defects at Gars NMJs we reviewed all of the non-DAP experiments seeking fibers where we were able to record MEPCs (i.e., innervated NMJs), but were unable to evoke an EPC (data not included in Fig. 2). This scenario was found in 17 of 179 NMJs $\left(7,6,4\right.$ Gars $^{\text {P278KY }}$ and Gars $^{\text {C201R }} 2$ and 4 months, respectively) including one or more occurrence $(\max =4)$ in 9 of the 18 mutant muscles $(6-12$ NMJs recorded per muscle). In contrast, for wild-type this situation arose at only 4 of 184 NMJs in 4 of 18 muscles and never occurred more than once in any experiment (6-11 NMJs/experiment).

Is the observed reduction in quantal content associated with fewer active release sites?

Voltage-clamp data reveal apparent presynaptic changes that cause a reduced quantal content as well as a reduced capacity for sustained release for mice carrying either Gars mutant allele. To investigate whether a reduced number of release sites could account for the lower quantal content and MEPC frequency at mutant NMJs, we stained LAL terminals for Bassoon, a presynaptic protein present at NMJ release sites (tom Dieck et al., 1998; see Materials and Methods for details, based on Nishimune et al., 2004). We used only LAL muscles from 2-month-old Gars ${ }^{P 278 K Y}$ mice with the rationale that, if release sites were contributing, it would be clearly evident at synapses of the most severely affected muscles. Wild-type terminals showed complete apposition of YFP-positive presynaptic terminals with postsynaptic receptors and bassoon-stained puncta in association with the presynaptic nerve (Fig. 4A-D). Consistent with the smaller size of the mutant mice/muscles (Seburn et al., 2006; Achilli et al., 2009), and reports for NMJs in other muscles (Sleigh et al., 2014), the mean area of LAL end plates in Gars ${ }^{P 278 K Y}$ mice was significantly smaller (Fig. 4I, compare solid and dashed vertical lines). However, the range in counts of the bassoon-stained puncta was similar for wild-type and Gars ${ }^{P 278 K Y}$ terminals (Fig. 4I, solid vs open) and there was no significant change $(p=0.4)$ in either the average absolute number (Fig. 4I, solid and dashed horizontal lines) or density of release sites ( $p \geq 0.17$; Fig. $4 J)$ compared with wild-type terminals. As expected from the initial morphological analysis of mutant NMJs (Fig. 1) 10 of the 34 terminals that were sampled from Gars ${ }^{P 278 K Y}$ muscles for this analysis had a portion of postsynaptic receptors not apposed by the presynaptic nerve and without bassoon-puncta. Although these terminals clearly lacked bassoon-stained puncta in the partially denervated regions, the relative proportion of the junction affected was not large ( $\leq 15 \%$; Fig. $4 H, K)$ so the effect on puncta counts was small. Counts for the 10 partially denervated junctions had a similar mean, median and range as those without any evident loss of presynaptic nerve (mean $=689$ vs 720 , median $=616$ vs 632 , range $=233-2049$ vs $134-1840)$. Together, these data show that release sites in Gars ${ }^{P 278 K Y}$ muscles are retained so long as the presynaptic terminal persists. Therefore, at partially denervated LAL junctions release sites could be reduced in proportion to the extent of partial denervation. However, other factors must also contribute because half of the NMJs in 2-month-old Gars ${ }^{P 278 K Y}$, and $\sim 85 \%$ in Gars ${ }^{C 201 R}$ LAL muscles, retain complete innervation (Fig. 1).

\section{Vesicle number and localization}

Given that a change in the number of release sites was insufficient to account for changes observed in evoked release, we next used electron microscopy to compare vesicle parameters at wild-type (Fig. 5A) and NMJs from the severely affected Gars ${ }^{P 278 K Y}$ (Fig. $5 B)$. We analyzed electron micrographs of portions of 5-10 NMJs (median 8) from each of five animals per genotype. Consistent with the lack of difference in MEPC amplitude, vesicle size was similar for mutant and wild-type terminals $(50 \pm 0.71$ vs $54 \pm$ 1.2, respectively). Average vesicles counts tended to be lower at Gars $^{P 278 K Y}$ NMJs compared with wild-type, but due to large inter-animal variation, for both genotypes, the difference did not quite reach our statistical cutoff for significance ( $p=0.08$; Fig. $5 C$, inset). However, consistent with light microscopy results above (Fig. 4I) and other work (Sleigh et al., 2014; their Figs. 3D, $6 C$; Gars ${ }^{C 201 R}$ and Gars $^{P 278 K Y}$, respectively), Gars ${ }^{P 278 K Y}$ mutant synapses are smaller than wild-type and therefore, the areas of captured portions of mutant NMJs in our electron micrographs also tended to be smaller ( mean $=14 \mathrm{vs} 28 \mu \mathrm{m}^{2}$, respectively, $p=$ 0.04 ). When vesicle number is plotted against area (Fig. $5 C$ ) it is evident that mutant muscle had fewer terminals with areas $>20$ $\mu \mathrm{m}^{2}$ and vesicle counts $>250$ (Fig. $5 C$, ellipse), and a preponderance of small $\left(<20 \mu \mathrm{m}^{2}\right)$ terminals with vesicle counts of $<150$ (Fig. $5 C$, inset). In general, mutant vesicle number still scaled 


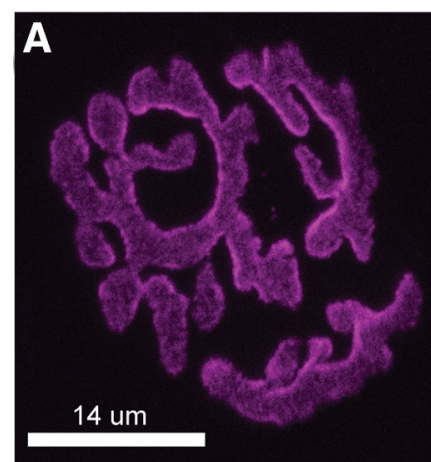

$\mathbf{E}$
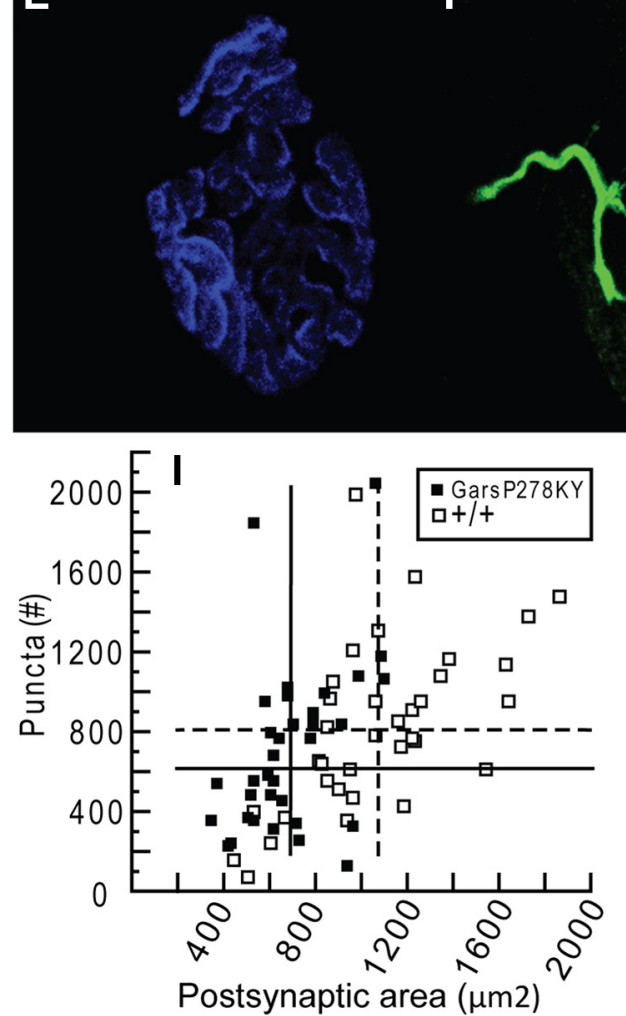

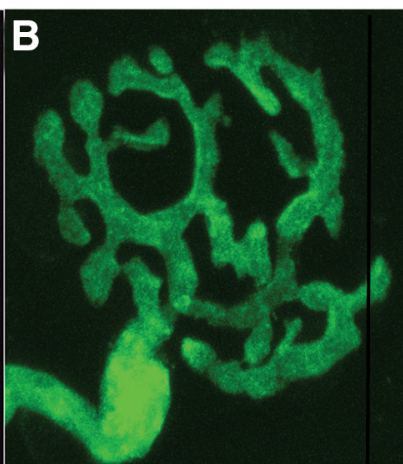

$\mathbf{F}$

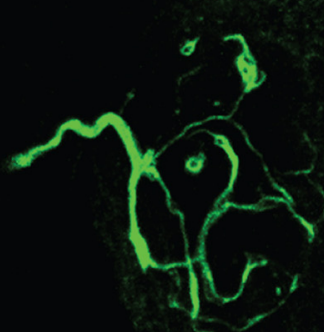

C

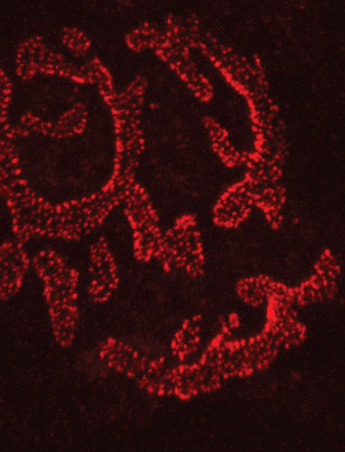

G

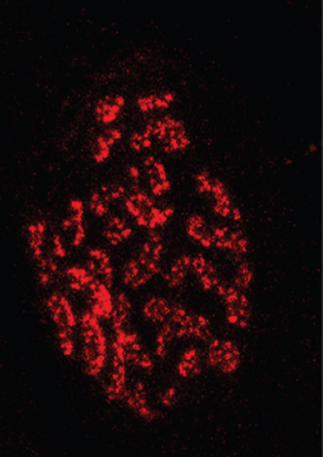

D

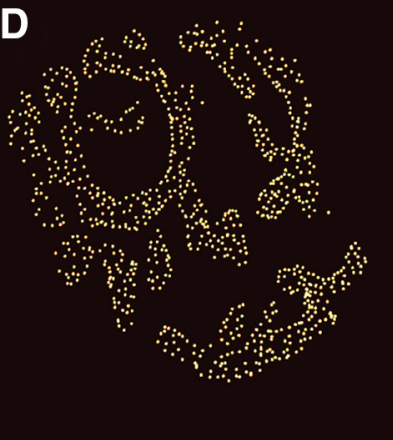

H
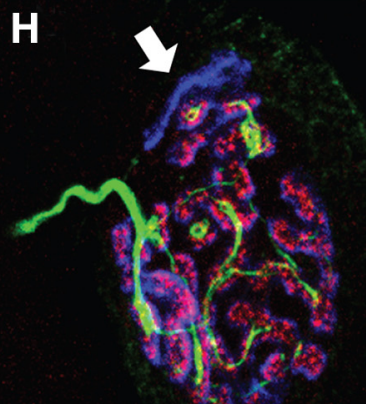

Figure 4. Quantification of bassoon-stained release sites in 2-month-old Gars ${ }^{P 278 K Y}$ LAL muscles. Process of visualization and quantification of bassoon-stained release sites is shown for a wild-type LAL terminal $(\boldsymbol{A}-\boldsymbol{D})$. Analysis included assessment of: $(\boldsymbol{A})$ the postsynaptic receptor area, $(\boldsymbol{B})$ presence of presynaptic nerve, and $(\boldsymbol{C})$ bassoon-stained puncta. Puncta were identified using a three-step process to render a 3D image (D) for automated counting of release sites (Imaris; see Materials and Methods for details). Typical Gars ${ }^{P 27 K K}$ NMJ $(\boldsymbol{E}-\boldsymbol{H})$ have more diffuse postsynaptic staining $(\boldsymbol{E})$, apposed by a thinned presynaptic nerve $(\boldsymbol{F})$, that nonetheless retains bassoon-stained puncta $(\boldsymbol{G})$ at innervated locations (NB, the areas where YFP appears to not overlie bassoon labeling are due to the faint YFP signal in portions of the axon and the thresholding of the image; at higher gain YFP was detectable in the vicinity of all bassoon-stained puncta). However, as expected, when a portion of the presynaptic nerve vacates, bassoon-stained release sites are no longer evident (merged image $\boldsymbol{H}$, arrow; expanded in $\boldsymbol{K}$ ). Gars ${ }^{P 278 K Y}$ sample included a total of 34 synapses that included 10 terminals with small areas of evident partial denervation. $I$, Scatterplot shows NMJ area and counts of bassoon-positive puncta at individual synapses of Gars ${ }^{P 278 K Y}$ (solid) and wild-type (open) NMJs. Vertical and horizontal lines indicate sample means (Gars ${ }^{P 28 K Y}$ and wild-type, solid and dashed, respectively). Mean area of LAL NMJs was significantly smaller ( $p<$ 0.002 ) compared with wild-type (solid vs dashed vertical line). Individual puncta counts covered a similar range and neither mean counts (dashed and solid horizontal lines) nor density $(J)$ were significantly different between genotypes ( $p=0.4$ and 0.17 , respectively). Analysis included $5-10$ (mean $=7$ ) terminals from each of five LAL muscles of each genotype $\left(n=34\right.$ and 35, Gars ${ }^{P 278 K Y}$ and wild-type, respectively). Statistical comparisons used a nested ANOVA.

with terminal area as the density of the vesicles (number $/ \mu \mathrm{m}^{2}$ ) was not different from wild-type (Fig. 5D). However, there are several examples of mutant terminals with vesicle counts below any found at wild-type terminals (Fig. 5C, inset, ellipse). Thus, despite the fact that the comparison of average wild-type and mutant vesicle counts did not reach our statistical cutoff, we contend that quantal content is likely limited by vesicle number for at least some terminals among the generally smaller $\operatorname{Gars}^{P 278 K Y}$ mutant terminals. Note, however, that the micrograph in Figure $5 B$ is an example from among those terminal portions that were clearly "depleted" in the Gars ${ }^{P 278 K Y}$ muscles. In a preliminary study we also examined two mutant muscles ( $5 \mathrm{NMJs}$ each, data not shown) from the distal plantaris muscle, which has more severe NMJ dysmorphology than the proximal LAL, and terminals such as shown in Figure $5 B$ were not found. Thus, such terminals should be considered worst-case, and if present at all, are not widespread even in the more severely affected distal plantaris of the mild Gars ${ }^{\text {C201R }}$ allele.

To complete our electron microscopy analysis of vesicles we evaluated their location relative to the presynaptic membrane. 

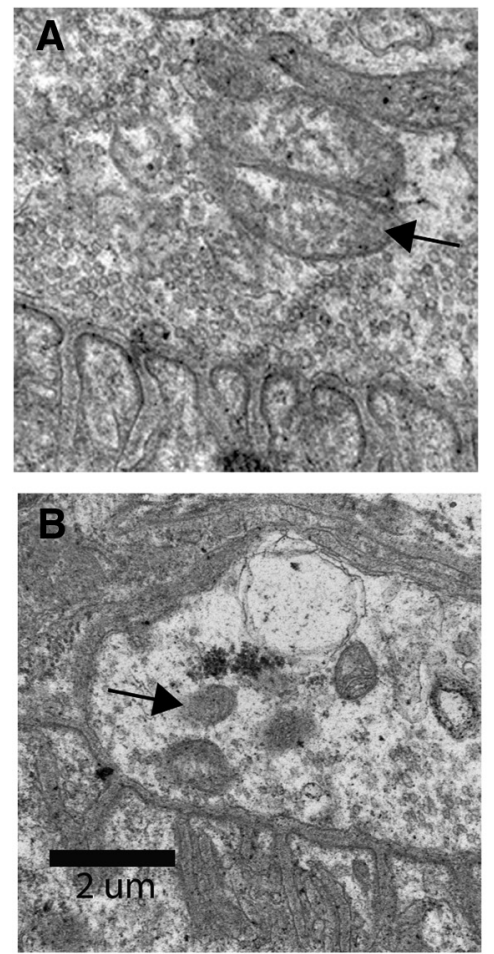

C

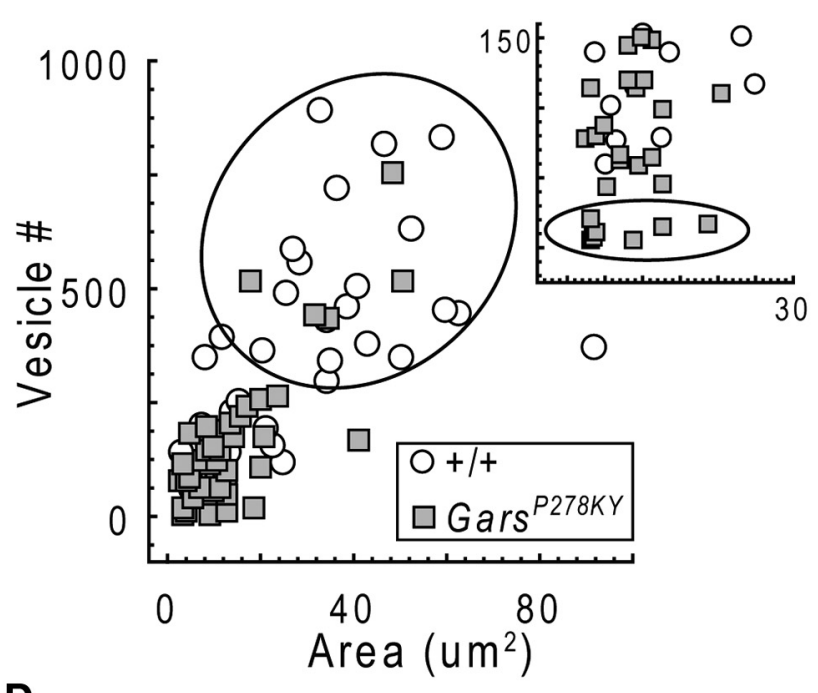

E

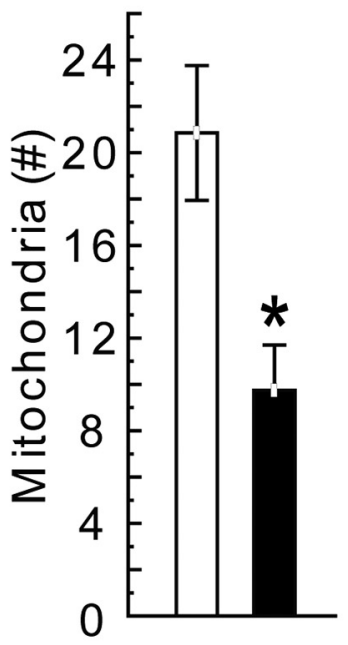

D

\begin{tabular}{|l|c|c|c|c|}
\hline & Density(\#/um2) & Count (\#/200nm) & Count (\#/20nm) & Count(\#/20nm/um) \\
\hline$+/+$ & $15 \pm 1.4$ & $45 \pm 3$ & $8 \pm 1$ & $1.2 \pm 0.1$ \\
\hline GarsP278KY & $13 \pm 1.5$ & $38 \pm 4$ & $7 \pm 1$ & $7 \pm 0.3$ \\
\hline
\end{tabular}

Figure 5. Electron microscopic analysis of NMJs. Electron micrographs of NMJs from LAL muscles of 2-month-old (A) wild-type and ( $\boldsymbol{B})$ Gars ${ }^{P 278 K Y}$ mice were captured (5 animals per genotype, 5-10 NMJs (median 8 per muscle). Mutant NMJ shown is representative of a "severely" affected NMJ with a low-vesicle count. Note junctional folds and other synaptic specializations are still evident at mutant synapses. Analysis showed vesicle size was similar for mutant and wild-type terminals ( $50 \mathrm{vs} 54 \mathrm{~nm}$, respectively; data not shown). C, Scatterplot shows that the area of terminal portions analyzed scale with vesicle counts for both genotypes. Note the relative absence of large, high vesicle count terminals (ellipse) and the preponderance of small, low vesicle count NMJs in the mutant ( $C$, lower quadrant; expanded in inset). Counts at some mutant NMJs were lower than values recorded at any wild-type NMJ (inset, ellipse). However, due to large inter-animal variability for both genotypes differences in average vesicle counts for wild-type and Gars ${ }^{P 27 K K Y}$ NMJs $(p=0.08)$ were not statistically different (see Results). $\boldsymbol{D}$, The density of the vesicles present in Gars ${ }^{P 278 K Y}$ terminals was not different from wild-type. Detailed analysis of vesicle location revealed no differences in the number of docked vesicles (within $20 \mathrm{~nm}$ ), or within $200 \mathrm{~nm}$ for either absolute or normalized counts (per micron of membrane). $\boldsymbol{E}$, Average counts of mitochondria $\left(\boldsymbol{A}, \boldsymbol{B}\right.$, arrows) were significantly lower at Gars ${ }^{P 278 K Y}$ terminals (median14 vs 6, wild-type and Gars ${ }^{P 278 K Y}$, respectively).

We counted the number of vesicles within $200 \mathrm{~nm}$ of the presynaptic membrane and the number of docked vesicles (within 20 $\mathrm{nm}$ ) and found no significant changes at mutant terminals for either absolute counts or counts normalized per micron of presynaptic membrane (Fig. 5D).

Finally, we also counted the number of identifiable mitochondria visible in electron micrographs. Interestingly, on average, there were significantly fewer mitochondria observed at Gars $^{P 278 K Y}$ terminals compared with wild-type (Fig. 5E). However, there was wide variation in counts from terminal to terminal for both genotypes, but the median was also shifted (14 vs 6 , Gars $^{P 278 K Y}$ and wild-type, respectively) suggesting the reduction in the mean number of mitochondria observed at NMJs of CMT2D mice was not due to a small number of mutant terminals with very few or no mitochondria.

Together, electron microscopy analysis of NMJs suggests that smaller terminals with fewer vesicles likely contributes to lower quantal content for at least a portion of NMJs in muscles of the severe Gars ${ }^{P 278 K Y}$ mice. Vesicles at mutant terminals were of normal size and were localized to the presynaptic membrane similar to wild-type, suggesting vesicle processing/trafficking is operating normally at CMT2D NMJs.

Enhancing synaptic function improves wire-hang performance of CMT2D mice

Prior work has shown that CMT2D mice have significant muscle weakness (Seburn et al., 2006; Achilli et al., 2009; Motley et al., 2011). Our data reveal significant synaptic dysfunction that could contribute to weakness in the CMT2D mice, so we next tested whether enhancing synaptic function could improve in vivo performance of the Gars mutants in a task requiring strength. We first confirmed that mutant synapses were capable of responding to the two test drugs in vitro: 3,4-DAP (amifampridine), which acts presynaptically to increase quantal content (Thomsen and Wilson, 1983), and physostigmine (eserine), which acts postsynaptically to enhance current duration at postsynaptic receptors (Shaw et al., 1985). In vitro recordings confirmed that both drugs acted as predicted to increase EPC amplitude at 4 month

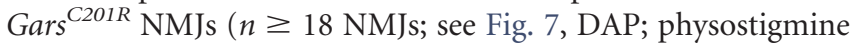
data not shown). We next evaluated whether the enhanced synaptic currents could translate to better whole animal performance on the wire-hang test. Mice first performed an initial wire-hang and then were injected with 3,4-DAP, physostigmine, or saline vehicle and retested $60 \mathrm{~min}$ later. We first tested the more mildly affected Gars ${ }^{C 201 R}$ mice and found that administration of physostigmine significantly improved wire-hang times, whereas 3,4-DAP caused a significant decrease (Fig. 6A,1 month) or no change (Fig. $6 B, 4$ months) in performance. Gars ${ }^{P 278 K Y}$ mice also showed improved wire-hang times after physostigmine administration (Fig. 6C). However, because the more severe disease causes them to perform so poorly in general, (latency to fall $\leq 8 \mathrm{~s}$ ) we did not test 3,4-DAP to see if it decreased performance in the Gars ${ }^{P 278 K Y}$ mice.

The improved performance of CMT2D mice after administration of physostigmine, the lack of improved performance in the 


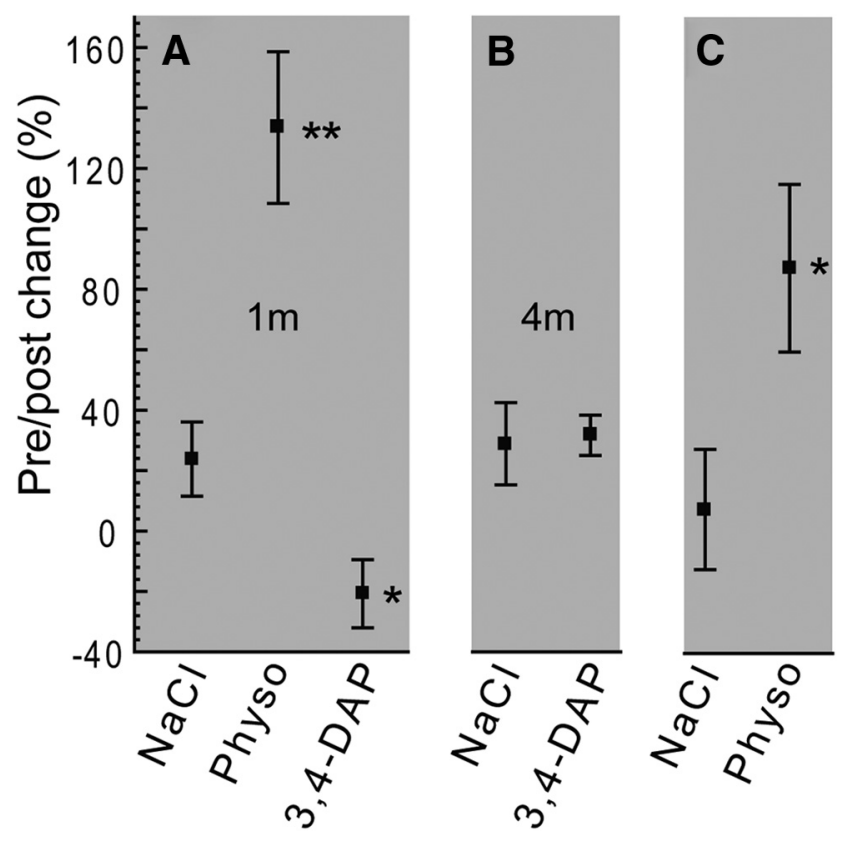

Figure 6. Wire-hang performance of CMT2D mice. Performance is expressed as the percentage change in wire-hang time after treatment ([(post-pre)/post] $] / 100$; see Materials and Methods for protocol details). $\boldsymbol{A}$, Gars ${ }^{\text {C201R }}$ mice (1-month-old) were able to perform better with physostigmine (postsynaptic), but showed a decrease in performance after administration of 3,4-DAP (presynaptic) or (B) no change to 3,4 DAP injection at 4 months of age. C, Gars ${ }^{P 278 K Y}$ mice showed a similar response to physostigmine, but were not tested with 3,4 DAP. Mice were 30- to 40-d-old for testing ( 1 and 4 month: Gars ${ }^{\text {C201R }}, n=6 ;+1+, n=5$; Gars ${ }^{P 278 K Y}, n=5$; $+/+, n=4)$. Wild-type $(+/+)$ mice typically perform the task to completion ( $60 \mathrm{~s}$ max) and showed no drug-related change in performance at the dosages used (physostigmine, $0.1 \mathrm{mg} /$ $\mathrm{kg} ; 3,4 \mathrm{DAP}, 2.5 \mathrm{mg} / \mathrm{kg}$ ), so data are not shown. Pairwise comparisons drug-treated versus $\mathrm{NaCl}$ with Student's $t$ test; ${ }^{* *}\left(t_{(9)}=4.2, p<0.01 ;{ }^{*} t_{(8)} \geq 2.3, p \leq 0.047\right)$.

presence of 3,4-DAP, and the existence of evident failures in evoked release with $1 \mathrm{~s}$ long trains, are consistent with a presynaptic defect that can be counteracted by enhanced activation of postsynaptic receptors, but limited capacity for increasing or maintaining quantal content.

\section{Quantal analysis in the presence of 3,4 DAP}

To assess the capacity of mutant NMJs to increase quantal release, we performed an additional set of voltage-clamp experiments using muscles from Gars ${ }^{C 201 R}$ to assess NMJ function in the presence $20 \mu \mathrm{M}$ 3,4 DAP. The data presented in Figure 7 show that mutant NMJs in 2- and 4-month-old LAL muscles are able to respond to the 3,4 DAP in a manner that is qualitatively similar to wild-type NMJs (note control values are replotted from Fig. 2). Lengthening the presynaptic depolarization increased EPC amplitude at mutant NMJs to values similar to control (Fig. 7C). However, mean quantal content at mutant 2-month-old NMJs remained significantly lower than the respective wild-type mean (Fig. 7D) and though it was still visibly reduced at 4-month-old mutant NMJs, it was not statistically different. Thus, in response to a single stimulus, mutant NMJs have the capacity to respond to 3,4 DAP and normalize EPC amplitude and increase quantal content to values at or near control. So why was wire-hang performance not improved by in vivo administration of 3,4 DAP? By the end of the $200 \mathrm{~ms} 50 \mathrm{~Hz}$ stimulation, the $20 \mu \mathrm{M} \mathrm{3,4} \mathrm{DAP} \mathrm{reduced}$ EPC amplitude to just 20\% of initial values for both mutant and wild-type NMJs (Fig. 7E). To improve the wire-hang performance of the mutants would require an improvement in sustained release for up to a minute, so an equivalent in vivo dose would be expected to worsen performance. To examine this further we also calculated the quantal content of the last EPC (10th) in the $50 \mathrm{~Hz}$ train (Fig. $7 F$ ). Under non-drug control conditions quantal content of the 10th EPC is significantly lower at mutant NMJs than wild-type (Fig. 7F, compare control mutant vs wildtype). Importantly, introduction of 3,4 DAP reduces quantal content even further at mutant NMJs and even reduces wild-type quantal content to values similar to those seen at mutant NMJs. Thus, despite the capacity of mutant and wild-type NMJs to increase their quantal release in the presence of 3,4 DAP (Fig. 7C), release is not well sustained for even $200 \mathrm{~ms}$ of $50 \mathrm{~Hz}$ stimulation and, at least at the dose tested, would not be effective in the treatment of the presynaptic defect in the Gars mutant mice.

\section{Discussion}

The objective of this study was to determine whether NMJ dysfunction is a previously unrecognized aspect of CMT2D and could therefore present a novel treatment avenue using drugs available for treatment of neuromuscular disorders characterized by reduced presynaptic release. Overall, our data confirm the presence of a presynaptic defect at the mutant NMJs that likely contributes to muscle weakness and can be overcome by administration of the cholinesterase inhibitor physostigmine. To our knowledge, this is the first detailed examination of NMJ function in a type 2 axonal CMT.

We studied the relatively mildly affected proximal LAL muscle from animals carrying two different Gars mutations that produce disease phenotypes in mice that vary, as does CMT2D, from mild $\left(\right.$ Gars $\left.^{C 201 R}\right)$ to severe $\left(\right.$ Gars $\left.^{P 278 K Y}\right)$. These new data describing synaptic defects are consistent with other previously described phenotypes (Seburn et al., 2006; Achilli et al., 2009; Motley et al., 2011; Stum et al., 2011; Sleigh et al., 2014) insofar as the different mutations did not produce distinct NMJ phenotypes, but rather produced changes that vary along a continuum both within and across genotype/age. As such, we propose these data represent at least a portion of a spectrum of NMJ dysfunction that, if present in patients, could present differently in each patient and to varying degrees at different times. The spectrum is evident within the LAL and would likely be expanded if examined across muscles because morphological data for the NMJ in CMT2D mice has consistently shown that distal muscles (lumbricals, tibialis anterior, plantaris) have more marked degeneration than NMJs in more proximal muscles (transversus abdominis, levator auris longus; Seburn et al., 2006; Achilli et al., 2009; Motley et al., 2011; Sleigh et al., 2014). Based on the more prevalent distal partial denervation alone, it is reasonable to assume that NMJ dysfunction in our mice is likely worse in distal muscles, a notion that is also consistent with disease presentation in humans (Saporta and Shy, 2013).

Together, these data indicate that the mutant GARS has a broad effect that leaves the fundamental release machinery intact but "weakens" NMJ function in the CMT2D mice. Overall, the results point clearly to a presynaptic problem that reduces quantal content, but examination of key determinants of quantal content did not reveal a primary mechanism. Instead, our data suggest that release processes overall are not functioning optimally and that dysfunction includes a spectrum of effects that for a given NMJ could include: (1) reduced terminal areas that may contain fewer total vesicles (inset Fig. 5C), and (2) morphological breakdown of the presynaptic nerve including some loss of associated release sites (Fig. 4K). For example, despite statistical differences in average vesicle number not reaching the 5\% statistical cutoff, it seems clear that reduced vesicle number could contrib- 

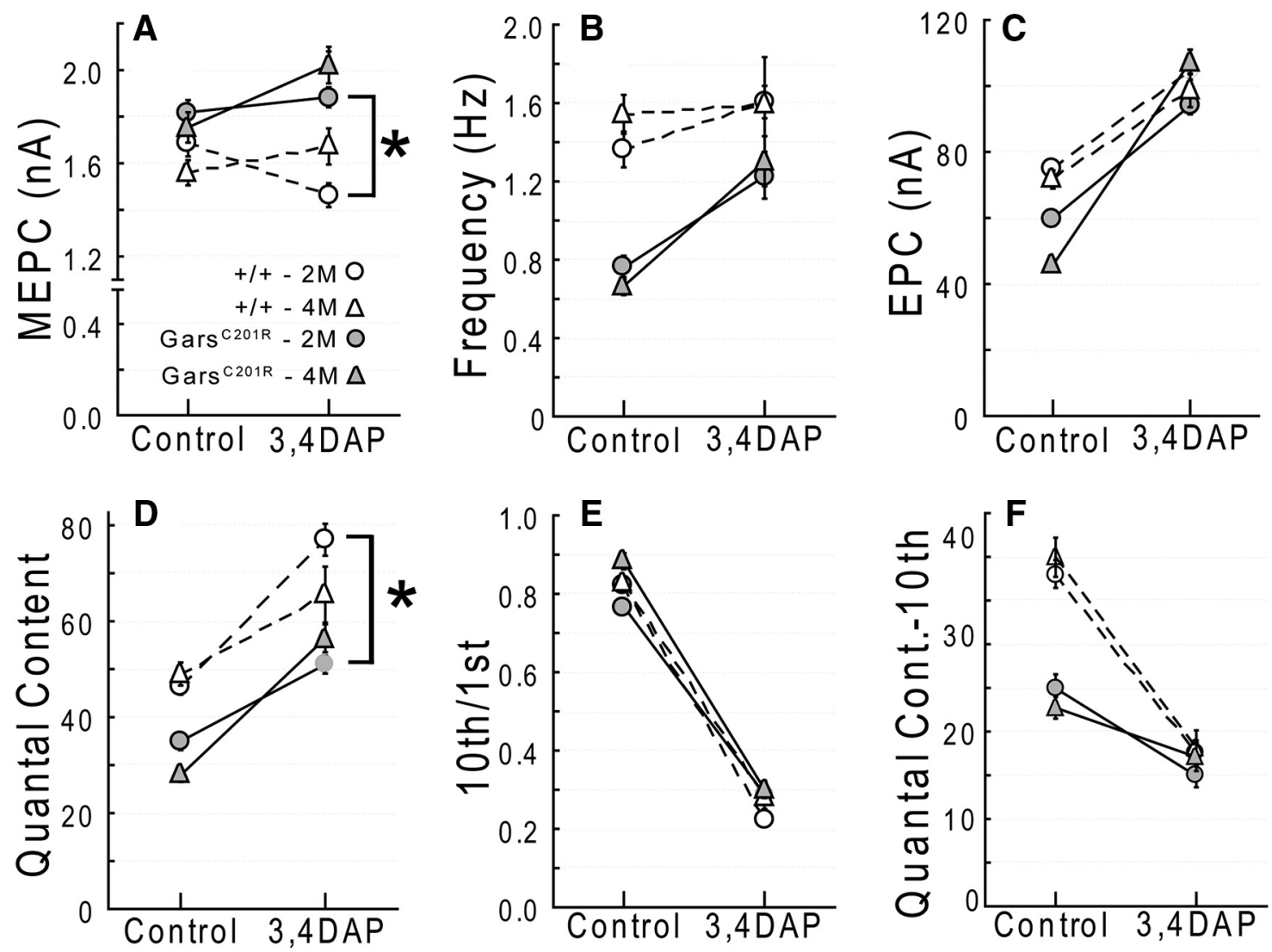

Figure 7. Quantal analysis in the presence of 3.4 DAP. Voltage-clamp experiments were conducted on cohorts of 2- and 4-month-old Gars ${ }^{\text {C201R }}$ and wild-type mice with 3,4 DAP added to the bath $(20 \mu \mathrm{M})$. Dashed lines are wild-type, solid lines are Gars ${ }^{\mathrm{C} 201 R}$, and 2 and 4 month data are shown with circles and triangles, respectively. Control values without DAP are re-plotted from Figure 2.A-E, The addition of 3,4 DAP to prolong presynaptic depolarization caused qualitatively similar changes at mutant and wild-type NMJs. Differences that existed between mutant and wild-type measures without 3,4 DAP (Fig. 2) were eliminated at 4-month-old mutant NMJs when 3,4 DAP was present, although quantal content was still somewhat lower. At 2-month-old mutant NMJs, quantal content remained significantly lower $(p=0.01$ ) compared with wild-type. $\boldsymbol{F}$, Quantal content calculated for the final ( 10 th) $50 \mathrm{~Hz}$ pulse was reduced by $3,4 \mathrm{DAP}$ in both wild-type and mutant.

ute at some NMJs, at least in the severe Gars ${ }^{P 278 K Y}$ allele (Fig. 5C). However, if reduced vesicle number was the sole disease mechanism for mutant Gars we would also have expected administration of 3,4 DAP to cause greater relative depression at Gars ${ }^{\mathrm{C} 201 R}$ NMJs than at wild-type with $50 \mathrm{~Hz}$ stimulation. Instead the relative depression induced by the 3,4 DAP was near identical (Fig. $7 E$ ). Similarly, although NMJ area is significantly smaller in distal Gars $^{P 278 K Y}$ muscles, in Gars ${ }^{\text {C201R }}$ muscles NMJ areas are not different from wild-type and do not change between 1 and 3 months of age (Sleigh et al., 2014, their Fig. 3), yet in our experiments quantal content is reduced between 2 and 4 months. Thus, reduced NMJ area likely contributes, but is also insufficient as a primary mechanism. Finally, although we found partially denervated NMJs where a reduction in the number of release sites could contribute to reduced quantal content, this too seems insufficient to account entirely for the observed dysfunction in both alleles. Although $\sim 50 \%$ of NMJs in the LAL of the severe Gars $^{P 278 K Y}$ allele are partially denervated, only $\sim 10 \%$ partial denervation is present in LAL of the mild Gars ${ }^{\mathrm{C201R}}$ allele at 4 months of age.

The paucity of mitochondria in mutant nerve terminals in our electron micrographs is also potentially interesting. Reduced mitochondria in terminals may influence synaptic transmission through a variety of mechanisms, including deficits in ATP production or changes in intracellular calcium dynamics (Stowers et al., 2002). The mitochondria that were present in Gars ${ }^{P 278 K Y}$ terminals were not vacuolated or other- wise obviously degenerating. Their reduced number may reflect a failure in axonal transport, biogenesis or turnover, but the association of MFN2 with CMT2A makes it clear that defects in neuronal mitochondria can directly lead to axonal neuropathy (Zuchner et al., 2004). The Gars gene in mammals encodes both the mitochondrial and cytosolic forms of the protein through alternative start codon usage (Shiba et al., 1994; Williams et al., 1995; Mudge et al., 1998). All mutations associated with CMT2D and neuropathy in humans and mice are in the common, downstream domains of the GARS protein that are shared by both isoforms. For most other tRNA synthetases, separate nuclear genes encode the mitochondrial and cytosolic enzymes and overall the genetics of tRNA synthetase-associated CMTs (Tolkunova et al., 2000; Scheper et al., 2007; Isohanni et al., 2010; Latour et al., 2010; McLaughlin et al., 2010; Vester et al., 2013) does not clearly indicate a mitochondrial basis for the neuropathies. Nonetheless, mitochondrial dysfunction, whether primary or secondary, also cannot be ruled out as contributing to the synaptic dysfunction we observed.

Our data also indicate ongoing, apparently compensatory changes in synaptic transmission at the NMJ. A variety of mechanisms could compensate for reduced synaptic currents to help maintain muscle function. The finding that the 4 month mutant NMJs again show some initial potentiation in response to $50 \mathrm{~Hz}$ activation may be an example of such compensation, but other changes may occur outside the synapse as well. We know that 
A

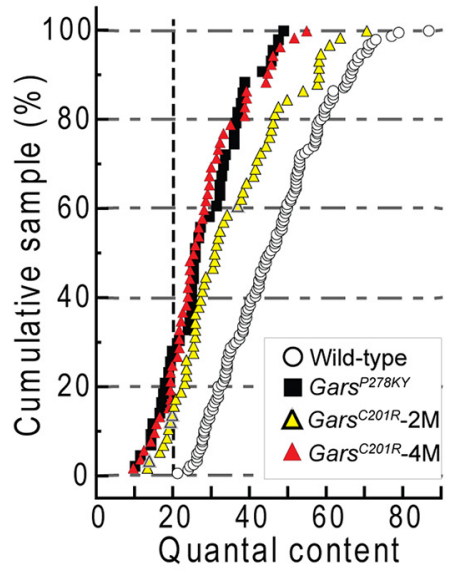

B

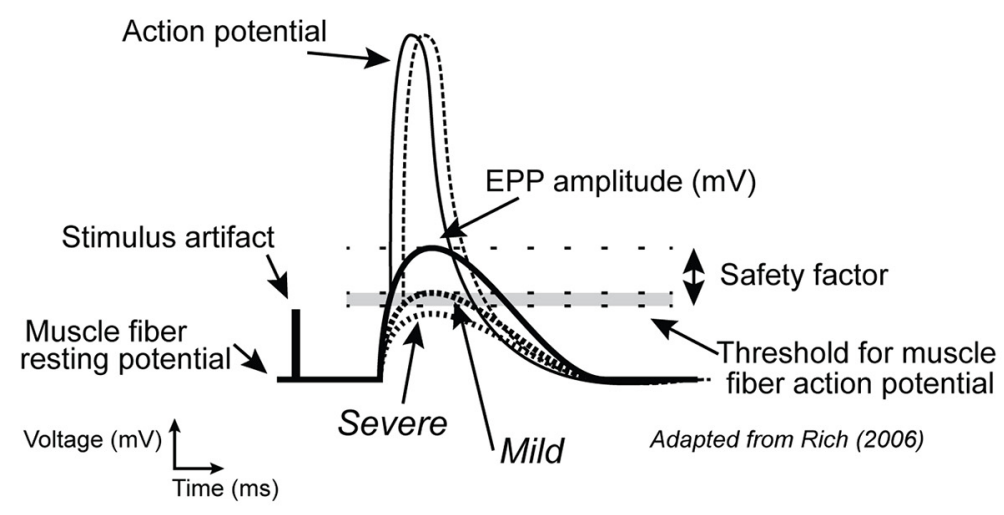

C $+/+$

$\operatorname{Gars}^{\mathrm{P} 278 K Y}$
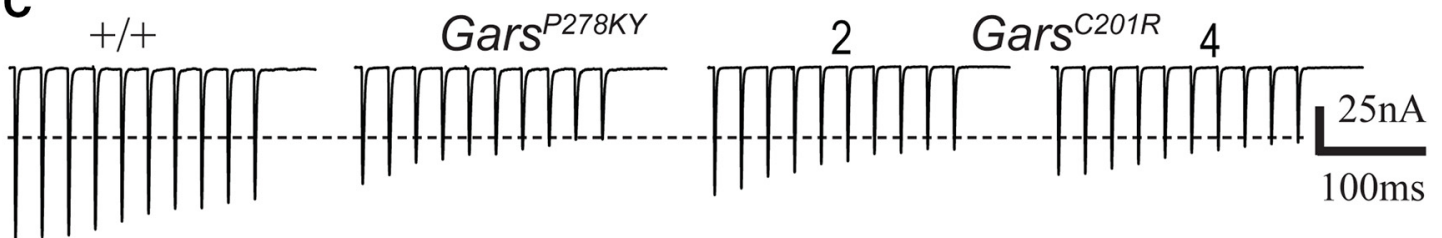

Figure 8. NMJ dysfunction in CMT2D mice. A, Plot of individual values for quantal content calculated for NMJs of each of the four experimental groups reveal CMT2D distributions are shifted to lower values compared with combined wild-type sample (white). Release at a proportion of terminals is severely reduced ( $\leq 20$, left of dashed vertical line), whereas the majority is mildly or moderately affected with quantal content values shifted to the left of the wild-type mean ( $\sim 50)$, whereas the highest wild-type values (60 -90) are largely absent for mutant NMJs. Note also, the 2 to 4 month progression at Gars ${ }^{(201 R}$ NMJs (yellow vs red) with the latter overlapping the distribution for severe Gars ${ }^{P 278 K Y}$. In $\boldsymbol{B}$, we show a hypothetical model of how the widespread NMJ dysfunction could produce variable and intermittent muscle weakness in CMT2D. Normal wild-type NMJs have a significant safety factor such that EPCs reliably depolarize the muscle above the threshold for an action potential (AP). In the CMT2D mice, terminals with a mild/moderate reduction in release (mild) would have a reduced safety factor and EPCs may intermittently fail to initiate an AP, whereas EPCs at severely affected terminals (severe) consistently do not reach the AP threshold. Note also, that because EPCs at affected terminals would initiate APs closer to their peak, APs would be slightly delayed (dotted AP) and EMG recordings of an affected muscle would be expected to display significant "jitter," a clinical measure used to identify transmission failure. C, Repetitive activation increases the extent and variability of transmission failure (Fig. 3). This scenario is depicted by example raw EPC traces of the $50 \mathrm{~Hz}$ response of moderately affected mutant terminals and typical wild-type. The horizontal dashed line through these traces indicates the EPC amplitude equivalent to a quantal content of 20 for the wild-type NMJ (equivalent to vertical dashed line in $A$ ). This cutoff was selected because all values measured at wild-type NMJs exceeded it, whereas $\sim 20 \%$ of the values for each mutant population were below it. For the $50 \mathrm{~Hz}$ trains shown wild-type the amplitude of final EPCs persists well above this level, but depression at mutant NMJs is sufficient to approach this value for the four to five final EPCS (Fig. 3D-G).

changes in muscle activity can modify passive properties of muscle (Lomo and Rosenthal, 1972) and such changes may occur in the CMT2D mice. Voltage-clamp measures are unaffected by changes in specific membrane resistance and capacitance or other changes (e.g., $\mathrm{Na}^{+}$channels) that could alter muscle excitability. Thus, while our voltage-clamp data definitively establish the presence of synaptic defects in the CMT2D mice, it is possible that muscle fiber characteristics or other processes might increase or decrease the likelihood of transmission failures that could contribute to weakness.

Based on the combined results presented here, we propose that CMT2D, and perhaps other type 2 axonal CMTs, display synaptic dysfunction that could contribute both variably and intermittently to weakness or fatigue. In wild-type mice, NMJs operate in a "failsafe" manner, such that firing the nerve produces sufficient depolarization in the muscle to cause an action potential without fail. This requires a "safety factor" of excess synaptic current to insure reliable muscle contraction (Paton and Waud, 1967; Rich, 2006). In the CMT2D mice, we show that average quantal content of mutant NMJs is significantly lower than wildtype (Fig. 2), and based on examination of distributions of mutant quantal content values, we propose a model of CMT2D synaptic transmission (Fig. 8) where disease processes diminish presynaptic release to a variable extent at most, if not all, NMJs. Distributions of quantal content at mutant NMJs each show a distinct leftward shift relative to wild-type, including between 15 and $30 \%$ of NMJs (depending on age and genotype) with a quantal content lower than any recorded at wild-type NMJs (Fig. 8A, left of vertical dashed line). We suggest currents at these severely affected NMJs could regularly fail to initiate muscle action potentials. At the other end of the range, fully $40 \%$ of wild-type NMJs have quantal contents $\geq 50$, whereas only $\sim 20 \%$ of values are in this range for NMJs in muscles of 2-month-old Gars ${ }^{\mathrm{C} 201 \mathrm{R}} \mathrm{mu}-$ tants, and for the NMJs in muscles of severe Gars ${ }^{P 278 K Y}$ and 4 month Gars ${ }^{C 201 R}$ mice, exactly 2 NMJs fall in this range. The extent to which the population of mutant NMJs with quantal contents within normal range contributes to transmission failures and therefore weakness is unknown. However, based on the failures observed at some 2-month-old Gars ${ }^{\mathrm{C} 201 R}$ mutant NMJs during sustained $1 \mathrm{~s}$ stimulation at $70 \mathrm{~Hz}$ (Fig. 3) and previously reported EMG decrements during in situ tetanic muscle contractions with $700 \mathrm{~ms} 80 \mathrm{~Hz}$ stimulation (Seburn et al., 2006, their Fig. $3 B$ ) it seems likely such failure is substantial. The diagram in Figure $8 B$ demonstrates how NMJs with severely reduced quantal content (e.g., Gars ${ }^{P 278 K Y}$ or 4 month Gars ${ }^{C 201 R}$ ) may not reach threshold for initiation of an action potential, even in the absence of failures. Actual raw traces from relatively mildly affected mutant NMJs in Figure 8C (also Fig. 3), demonstrate how depression during repetitive activation could reduce release below the safety factor and cause failure of muscle activation. 


\section{References}

Achilli F, Bros-Facer V, Williams HP, Banks GT, AlQatari M, Chia R, Tucci V, Groves M, Nickols CD, Seburn KL, Kendall R, Cader MZ, Talbot K, van Minnen J, Burgess RW, Brandner S, Martin JE, Koltzenburg M, Greensmith L, Nolan PM, et al. (2009) An ENU-induced mutation in mouse glycyl-tRNA synthetase (GARS) causes peripheral sensory and motor phenotypes creating a model of Charcot-Marie-Tooth type 2D peripheral neuropathy. Dis Model Mech 2:359-373. CrossRef Medline

Angaut-Petit D, Molgo J, Connold AL, Faille L (1987) The levator auris longus muscle of the mouse: a convenient preparation for studies of short- and long-term presynaptic effects of drugs or toxins. Neurosci Lett 82:83-88. CrossRef Medline

Antonellis A, Ellsworth RE, Sambuughin N, Puls I, Abel A, Lee-Lin SQ, Jordanova A, Kremensky I, Christodoulou K, Middleton LT, Sivakumar K, Ionasescu V, Funalot B, Vance JM, Goldfarb LG, Fischbeck KH, Green ED (2003) Glycyl tRNA synthetase mutations in Charcot-Marie-Tooth disease type $2 \mathrm{D}$ and distal spinal muscular atrophy type V. Am J Hum Genet 72:1293-1299. CrossRef Medline

Burgess RW, Cox GA, Seburn KL (2010) Neuromuscular disease models and analysis. Methods Mol Biol 602:347-393. CrossRef Medline

Charcot JM, Marie P (1886) Sur une forme particulière d'atrophie musculaire progressive, souvent familiale, debutant par les pieds et les jambes et atteignant plus tard les mains. Rev Med 6:97-138.

Cruz LJ, Gray WR, Olivera BM, Zeikus RD, Kerr L, Yoshikami D, Moczydlowski E (1985) Conus geographus toxins that discriminate between neuronal and muscle sodium channels. J Biol Chem 260:9280-9288. Medline

Del Bo R, Locatelli F, Corti S, Scarlato M, Ghezzi S, Prelle A, Fagiolari G, Moggio M, Carpo M, Bresolin N, Comi GP (2006) Coexistence of CMT-2D and distal SMA-V phenotypes in an Italian family with a GARS gene mutation. Neurology 66:752-754. CrossRef Medline

Dubourg O, Azzedine H, Yaou RB, Pouget J, Barois A, Meininger V, Bouteiller D, Ruberg M, Brice A, LeGuern E (2006) The G526R glycyl-tRNA synthetase gene mutation in distal hereditary motor neuropathy type $\mathrm{V}$. Neurology 66:1721-1726. CrossRef Medline

Dyck PJ (1975) Definition and basis of classification of hereditary neuropathy with neuronal atrophy and degeneration. In: Peripheral Neuropathy (Dyck PJ, Thomas PK, Lambert EH, eds), pp 825-867. Philadelphia, PA: WB Saunders.

Engel AG, Shen XM, Selcen D, Sine SM (2015) Congenital myasthenic syndromes: pathogenesis, diagnosis, and treatment. Lancet Neurol 14: 420-434. CrossRef Medline

Feng G, Mellor RH, Bernstein M, Keller-Peck C, Nguyen QT, Wallace M, Nerbonne JM, Lichtman JW, Sanes JR (2000) Imaging neuronal subsets in transgenic mice expressing multiple spectral variants of GFP. Neuron 28:41-51. CrossRef Medline

Glavinović MI (1979) Voltage clamping of unparalysed cut rat diaphragm for study of transmitter release. J Physiol 290:467-480. CrossRef Medline

Gomez CM, Maselli R, Gundeck JE, Chao M, Day JW, Tamamizu S, Lasalde JA, McNamee M, Wollmann RL (1997) Slow-channel transgenic mice: a model of postsynaptic organellar degeneration at the neuromuscular junction. J Neurosci 17:4170-4179. Medline

Guyton DL, Hambrecht FT (1974) Theory and design of capacitor electrodes for chronic stimulation. Med Biol Eng 12:613-620. CrossRef Medline

Isohanni P, Linnankivi T, Buzkova J, Lönnqvist T, Pihko H, Valanne L, Tienari PJ, Elovaara I, Pirttilä T, Reunanen M, Koivisto K, Marjavaara S, Suomalainen A (2010) DARS2 mutations in mitochondrial leucoencephalopathy and multiple sclerosis. J Med Genet 47:66-70. CrossRef Medline

James PA, Cader MZ, Muntoni F, Childs AM, Crow YJ, Talbot K (2006) Severe childhood SMA and axonal CMT due to anticodon binding domain mutations in the GARS gene. Neurology 67:1710-1712. CrossRef Medline

Kong L, Wang X, Choe DW, Polley M, Burnett BG, Bosch-Marcé M, Griffin JW, Rich MM, Sumner CJ (2009) Impaired synaptic vesicle release and immaturity of neuromuscular junctions in spinal muscular atrophy mice. J Neurosci 29:842-851. CrossRef Medline

Latour P, Thauvin-Robinet C, Baudelet-Méry C, Soichot P, Cusin V, Faivre L, Locatelli MC, Mayençon M, Sarcey A, Broussolle E, Camu W, David A, Rousson R (2010) A major determinant for binding and aminoacylation of tRNA(Ala) in cytoplasmic Alanyl-tRNA synthetase is mutated in dom- inant axonal Charcot-Marie-Tooth disease. Am J Hum Genet 86:77-82. CrossRef Medline

Lomo T, Rosenthal J (1972) Control of ACh sensitivity by muscle activity in the rat. J Physiol 221:493-513. CrossRef Medline

Magrassi L, Purves D, Lichtman JW (1987) Fluorescent probes that stain living nerve terminals. J Neurosci 7:1207-1214. Medline

McLaughlin HM,Sakaguchi R, Liu C, Igarashi T, Pehlivan D, Chu K, Iyer R, Cruz P, Cherukuri PF, Hansen NF, Mullikin JC; NISC Comparative Sequencing Program, Biesecker LG, Wilson TE, Ionasescu V, Nicholson G, Searby C, Talbot K, Vance JM, Züchner S, et al. (2010) Compound heterozygosity for loss-of-function lysyl-tRNA synthetase mutations in a patient with peripheral neuropathy. Am J Hum Genet 87:560-566. CrossRef Medline

Motley WW, Seburn KL, Nawaz MH, Miers KE, Cheng J, Antonellis A, Green ED, Talbot K, Yang XL, Fischbeck KH, Burgess RW (2011) CharcotMarie-Tooth-linked mutant GARS is toxic to peripheral neurons independent of wild-type GARS levels. PLoS Genet 7:e1002399. CrossRef Medline

Mudge SJ, Williams JH, Eyre HJ, Sutherland GR, Cowan PJ, Power DA (1998) Complex organisation of the 5 '-end of the human glycine tRNA synthetase gene. Gene 209:45-50. CrossRef Medline

Nishimune $H$ (2012) Active zones of mammalian neuromuscular junctions: formation, density, and aging. Ann N Y Acad Sci 1274:24-32. CrossRef Medline

Nishimune H, Sanes JR, Carlson SS (2004) A synaptic laminin-calcium channel interaction organizes active zones in motor nerve terminals. Nature 432:580-587. CrossRef Medline

Paton WD, Waud DR (1967) The margin of safety of neuromuscular transmission. J Physiol 191:59-90. CrossRef Medline

Plomp JJ, Vergouwe MN, Van den Maagdenberg AM, Ferrari MD, Frants RR, Molenaar PC (2000) Abnormal transmitter release at neuromuscular junctions of mice carrying the tottering alpha( $1 \mathrm{~A}) \mathrm{Ca}(2+)$ channel mutation. Brain 123:463-471. CrossRef Medline

Rafael JA, Nitta Y, Peters J, Davies KE (2000) Testing of SHIRPA, a mouse phenotypic assessment protocol, on $\operatorname{Dmd}(\mathrm{mdx})$ and $\operatorname{Dmd}(\mathrm{mdx} 3 \mathrm{cv})$ dystrophindeficient mice. Mamm Genome 11:725-728. CrossRef Medline

Rich MM (2006) The control of neuromuscular transmission in health and disease. Neuroscientist 12:134-142. CrossRef Medline

Rich MM, Waldeck RF, Cork LC, Balice-Gordon RJ, Fyffe RE, Wang X, Cope TC, Pinter MJ (2002) Reduced endplate currents underlie motor unit dysfunction in canine motor neuron disease. J Neurophysiol 88:32933304. CrossRef Medline

Robitaille R, Charlton MP (1992) Presynaptic calcium signals and transmitter release are modulated by calcium-activated potassium channels. J Neurosci 12:297-305. Medline

Rohkamm B, Reilly MM, Lochmüller H, Schlotter-Weigel B, Barisic N, Schöls L, Nicholson G, Pareyson D, Laurà M, Janecke AR, Miltenberger-Miltenyi G, John E, Fischer C, Grill F, Wakeling W, Davis M, Pieber TR, AuerGrumbach M (2007) Further evidence for genetic heterogeneity of distal HMN type V, CMT2 with predominant hand involvement and Silver syndrome. J Neurol Sci 263:100-106. CrossRef Medline

Saporta MA, Shy ME (2013) Inherited peripheral neuropathies. Neurol Clin 31:597-619. CrossRef Medline

Scheper GC, van der Klok T, van Andel RJ, van Berkel CG, Sissler M, Smet J, Muravina TI, Serkov SV, Uziel G, Bugiani M, Schiffmann R, KrägelohMann I, Smeitink JA, Florentz C, Van Coster R, Pronk JC, van der Knaap MS (2007) Mitochondrial aspartyl-tRNA synthetase deficiency causes leukoencephalopathy with brain stem and spinal cord involvement and lactate elevation. Nat Genet 39:534-539. CrossRef Medline

Seburn KL, Nangle LA, Cox GA, Schimmel P, Burgess RW (2006) An active dominant mutation of glycyl-tRNA synthetase causes neuropathy in a Charcot-Marie-Tooth 2D mouse model. Neuron 51:715-726. CrossRef Medline

Shaw KP, Aracava Y, Akaike A, Daly JW, Rickett DL, Albuquerque EX (1985) The reversible cholinesterase inhibitor physostigmine has channelblocking and agonist effects on the acetylcholine receptor-ion channel complex. Mol Pharmacol 28:527-538. Medline

Shen H, Barry DM, Dale JM, Garcia VB, Calcutt NA, Garcia ML (2011) Muscle pathology without severe nerve pathology in a new mouse model of Charcot-Marie-Tooth disease type 2E. Hum Mol Genet 20:2535-2548. CrossRef Medline

Shiba K, Schimmel P, Motegi H, Noda T (1994) Human glycyl-tRNA syn- 
theta: wide divergence of primary structure from bacterial counterpart and species-specific aminoacylation. J Biol Chem 269:30049-30055. Medline

Sivakumar K, Kyriakides T, Puls I, Nicholson GA, Funalot B, Antonellis A, Sambuughin N, Christodoulou K, Beggs JL, Zamba-Papanicolaou E, Ionasescu V, Dalakas MC, Green ED, Fischbeck KH, Goldfarb LG (2005) Phenotypic spectrum of disorders associated with glycyl-tRNA synthetase mutations. Brain 128:2304-2314. CrossRef Medline

Skre H (1974) Genetic and clinical aspects of Charcot-Marie-Tooth's disease. Clin Genet 6:98-118. Medline

Sleigh JN, Grice SJ, Burgess RW, Talbot K, Cader MZ (2014) Neuromuscular junction maturation defects precede impaired lower motor neuron connectivity in Charcot-Marie-Tooth type 2D mice. Hum Mol Genet 23:2639-2650. CrossRef Medline

Stowers RS, Megeath LJ, Górska-Andrzejak J, Meinertzhagen IA, Schwarz TL (2002) Axonal transport of mitochondria to synapses depends on Milton, a novel Drosophila protein. Neuron 36:1063-1077. CrossRef Medline

Stum M, McLaughlin HM, Kleinbrink EL, Miers KE, Ackerman SL, Seburn KL, Antonellis A, Burgess RW (2011) An assessment of mechanisms underlying peripheral axonal degeneration caused by aminoacyl-tRNA synthetase mutations. Mol Cell Neurosci 46:432-443. CrossRef Medline

Thomsen RH, Wilson DF (1983) Effects of 4-aminopyridine and 3,4diaminopyridine on transmitter release at the neuromuscular junction. J Pharmacol Exp Ther 227:260-265. Medline

Tolkunova E, Park H, Xia J, King MP, Davidson E (2000) The human lysyltRNA synthetase gene encodes both the cytoplasmic and mitochondrial enzymes by means of an unusual alternative splicing of the primary transcript. J Biol Chem 275:35063-35069. CrossRef Medline

tom Dieck S, Sanmartí-Vila L, Langnaese K, Richter K, Kindler S, Soyke A, Wex H, Smalla KH, Kämpf U, Fränzer JT, Stumm M, Garner CC, Gundelfinger ED (1998) Bassoon, a novel zinc-finger CAG/glutamine- repeat protein selectively localized at the active zone of presynaptic nerve terminals. J Cell Biol 142:499-509. CrossRef Medline

Tooth HH (1886) The peroneal type of progressive muscular atrophy. London: HK Lewis.

Vester A, Velez-Ruiz G, McLaughlin HM, Lupski JR, Talbot K, Vance JM, Züchner S, Roda RH, Fischbeck KH, Biesecker LG, Nicholson G, Beg AA, Antonellis A (2013) A loss-of-function variant in the human histidyltRNA synthetase (HARS) gene is neurotoxic in vivo. Hum Mutat 34:191199. CrossRef Medline

Wang X, Engisch KL, Li Y, Pinter MJ, Cope TC, Rich MM (2004) Decreased synaptic activity shifts the calcium dependence of release at the mammalian neuromuscular junction in vivo. J Neurosci 24:10687-10692. CrossRef Medline

Wang X, Li Y, Engisch KL, Nakanishi ST, Dodson SE, Miller GW, Cope TC, Pinter MJ, Rich MM (2005) Activity-dependent presynaptic regulation of quantal size at the mammalian neuromuscular junction in vivo. J Neurosci 25:343-351. CrossRef Medline

Wang X, Wang Q, Engisch KL, Rich MM (2010) Activity-dependent regulation of the binomial parameters $p$ and $n$ at the mouse neuromuscular junction in vivo. J Neurophysiol 104:2352-2358. CrossRef Medline

Williams J, Osvath S, Khong TF, Pearse M, Power D (1995) Cloning, sequencing and bacterial expression of human glycine tRNA synthetase. Nucleic Acid Res 23:1307-1310. CrossRef Medline

Zuchner S, Mersiyanova IV, Muglia M, Bissar-Tadmouri N, Rochelle J, Dadali EL, Zappia M, Nelis E, Patitucci A, Senderek J, Parman Y, Evgrafov O, Jonghe PD, Takahashi Y, Tsuji S, Pericak-Vance MA, Quattrone A, Battaloglu E, Polyakov AV, Timmerman V, et al. (2004) Mutations in the mitochondrial GTPase mitofusin 2 cause Charcot-Marie-Tooth neuropathy type 2A. Nat Genet 36:449-451. CrossRef Medline

Zucker RS, Regehr WG (2002) Short-term synaptic plasticity. Annu Rev Physiol 64:355-405. CrossRef Medline 